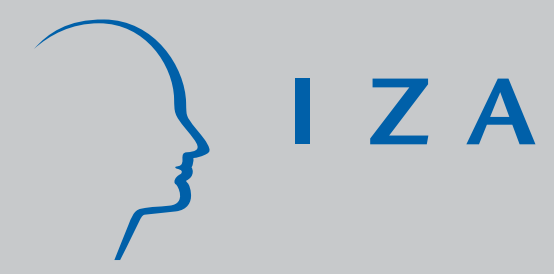

IZA DP No. 1445

In-Work Policies in Europe:

Killing Two Birds with One Stone?

Olivier Bargain

Kristian Orsini

December 2004 


\title{
In-Work Policies in Europe: Killing Two Birds with One Stone?
}

Olivier Bargain

\author{
IZA Bonn
}

and DELTA, Paris

Kristian Orsini

University of Leuven

Discussion Paper No. 1445

December 2004

\author{
IZA \\ P.O. Box 7240 \\ 53072 Bonn \\ Germany \\ Phone: +49-228-3894-0 \\ Fax: +49-228-3894-180 \\ Email: iza@iza.org
}

\begin{abstract}
Any opinions expressed here are those of the author(s) and not those of the institute. Research disseminated by IZA may include views on policy, but the institute itself takes no institutional policy positions.

The Institute for the Study of Labor (IZA) in Bonn is a local and virtual international research center and a place of communication between science, politics and business. IZA is an independent nonprofit company supported by Deutsche Post World Net. The center is associated with the University of Bonn and offers a stimulating research environment through its research networks, research support, and visitors and doctoral programs. IZA engages in (i) original and internationally competitive research in all fields of labor economics, (ii) development of policy concepts, and (iii) dissemination of research results and concepts to the interested public.
\end{abstract}

IZA Discussion Papers often represent preliminary work and are circulated to encourage discussion. Citation of such a paper should account for its provisional character. A revised version may be available directly from the author. 


\title{
ABSTRACT
}

\section{In-Work Policies in Europe: Killing Two Birds with One Stone?*}

\begin{abstract}
Earning an income is probably the best way of avoiding poverty and social exclusion, hence the recent trend of promoting employment through in-work transfers in OECD countries. Yet, the relative consensus on the need for 'making work pay' policies is muddied by a number of concerns relative to the design of the reforms and the treatment of the family dimension. Relying on EUROMOD, a EU-15 integrated tax-benefit microsimulation software, we simulate two types of in-work benefits. The first one is means-tested on family income, in the fashion of the British Working Family Tax Credit, while the second is a purely individualized policy. Both reforms are built on the same cost basis (after behavioral responses) and simulated in three European countries which experience severe poverty traps, namely Finland, France and Germany. The potential labor supply responses to the reforms and the subsequent redistributive impacts are assessed for each country using a structural discrete-choice model. We compare how both reforms achieve poverty reduction and social inclusion (measured as the number of transitions into activity). All three countries present different initial conditions, including institutional environment, existing tax-benefit systems and distribution of incomes and wages. These sources of heterogeneity are exploited together with different labor supply sensitivities to explain the cross-country differences in the impact of the reforms.
\end{abstract}

JEL Classification: $\quad$ C25, C52, H31, J22

Keywords: tax-benefit systems, in-work benefits, microsimulation, household labor supply, multinomial logit

Corresponding author:

Olivier Bargain

IZA Bonn

P.O. Box 7240

53072 Bonn

Germany

Email: bargain@iza.org

\footnotetext{
* We are grateful to Tim Callan for in-depth comments of the first draft. We also thank Tony Atkinson, Denis Beninger, François Bourguignon, Alan Duncan, Marc Gurgand, Seija and Pekka Ilmakunnas, Herwig Immervoll, François Laisney, Thierry Magnac, Thomas Picketty, Cathal O'Donoghue, Holly Sutherland, Alain Trannoy, Heikki Vittamäki and Sile O'Dorchai for useful comments and advices. All errors or omissions remain ours. This paper was written as part of the MICRESA (Micro Analysis of the European Social Agenda) project, financed by the Improving Human Potential programme of the European Commission (SERD-2001-00099). EUROMOD relies on the following microdata: Enquête Budget des Ménages made available by INSEE, the German Socio-Economic Panel Study made available by DIW and the Income Distribution Survey made available by Statistics Finland. We are indebted to our present and former colleagues Herwig Immervoll, Christine Lietz and Cathal O'Donoghue for their invaluable contributions to the construction of the EUROMOD. The paper was written when K. Orsini was working at DULBEA, Free University of Brussels.
} 


\section{Introduction}

Poverty has been reduced in many industrialized countries by the development of large-scale welfare systems which include generous social assistance schemes for the poorest. However, there is a well-known risk that the instruments used for this purpose generate social exclusion by making work financially unattractive, especially to less productive workers. Consequently, the recent trend in many OECD countries has been to promote self-sufficiency as the best way to escaping both poverty and social exclusion. At the institutional level, to provide protection against both plagues requires finding benefit schemes which not only guarantee sufficient income, but also make work financially at tractive, in comparison with remaining inactive or unemployed. To what extent and at which cost it is possible to improve existing tax-benefit systems in Europe on both accounts is the general subject of this paper.

More precisely, we shall focus on the difficult issues surrounding the design of in-work benefits in Europe. Following pioneering measures introduced in the US and the UK - the Earned Income Tax Credit (EITC hereafter) and the Working Family Tax Credit (WFTC hereafter) respectively -, several European countries have implemented policies aimed at 'making work pay'. Yet, the relative consensus on the need for this type of reforms is muddied by concerns about efficient policy design, given the framework conditions and the general objectives pursued. In particular, the treatment of the family dimension is a crucial issue which has only been superficially explored. Policies which are means-tested on household income, such as the EITC or the WFTC, are known to be well targeted at households in need but may also discourage the work of secondary-earners, most often women. Individualized schemes seem to combine more unambiguous incentive effects with less efficient targeting. Whether redistributive and efficiency objectives can be reconciled in a single policy measure is still an open question.

In this paper, we address these aspects in a comprehensive way by comparing the effects of two reforms in three European countries - Finland, France and Germany - all experiencing inactivity traps. Using the integrated microsimulation of European tax-benefit systems (EUROMOD), we simulate the reforms for each country. The first policy is a purely individualized in-work transfer while the second is an extended version of the WFTC.

To analyse the potential effects on incentives and redistribution, we combine the microsimulation with structural models of labor supply. The reform scenarios are tailored to reach the same budgetary cost - after potential behavioral responses - so that both cross-country and cross-reform comparisons are allowed.

To clarify policy analysis, we compare the reforms in the light of two clear-cut policy goals, namely poverty reduction and social inclusion. The first objective aims at reducing the share of households whose income is lower than the pre-reform poverty line while the second simply aims at maximizing the number of transitions into work after the reform. Specifically, we question which of the suggested in-work benefits succeeds best on each account and whether the incentive effect of in-work transfers is significant in poverty reduction. More broadly, we discuss what can be achieved given each country's social policy agenda.

In our view, this paper is one of the very first to tackle the issue of in-work policies in a comprehensive international perspective. More generally, it contributes to the literature on cross-country tax analyses in two ways.

Firstly, national and international studies related to tax-benefit systems rely too often on case-studies with hypothetical households. Instead, large-scale conclusions require the use of microsimulation models in order to assess precisely the overall incentive and redistributive impacts of alternative policies. Yet, few 
studies conduct such comprehensive evaluation in an international perspective. ${ }^{1}$ To our knowledge, there are even fewer cross-country studies which combine microsimulation and labor supply models. Spadaro (2004) extends the work of Bourguignon and al. (1997) by introducing behavioral responses into the simulations under several assumptions about the size of labor supply elasticities. ${ }^{2}$ Other studies rely on more traditional econometric estimations, like Callan, Dex, Smith and Vlasblom (1999) and Aaberge, Colombino and Strøm (2000). ${ }^{3}$ While the number of national studies using behavioral microsimulation increases dramatically, the scarcity of similar analyses in a cross-country perspective can easily be explained by the difficulty to obtain comparable information for several countries. The datasets we relied upon have been rendered homogenous and the labor supply estimations conducted with similar specifications. In addition, the integrated microsimulation program accounts for the whole complexity of the European tax benefit systems. Such a consistent framework offers a unique chance to perform cross-country analysis in a robust and truly comparative way.

Secondly, the success of a tax-benefit reform (and an in-work policy in particular) depends crucially on its design in relation with the initial conditions. These include the institutional framework - in particular the existing tax-benefit system -, the distribution of wage rates and incomes in the country as well as the size and distribution of the labor supply elasticities. Even though the importance of these conditions has been stressed in previous studies, they have not been sufficiently exploited in large-scale analyses and even less so within multi-country comparative framework. ${ }^{4}$ The present paper attempts to contribute significantly on this account and provides useful guidelines for the design of MWP policies.

The layout of the paper is as follows. In section 2, we present the recent trend in policies aimed at 'making work pay' in Europe. Section 3 outlines the structure of two types of in-work transfers and details the choices made regarding the simulations and the design of these policies. In Section 4, the initial conditions are closely analysed and provide useful intuitions to explain the results. In particular, we compare estimated elasticities with the related findings in the literature for each country. Section 5 analyses the potential effects of the reform on incentives and redistribution and suggests interpretations of the cross-country and cross-reform differences. Section 6 concludes.

\section{In-work Policies in Europe}

'Making Work Pay' (MWP) policies have been suggested primarily to offset the disincentive effects of generous social assistance schemes on employment. In this first section, we recall the presumed importance of inactivity traps, followed by a brief summary of the recent trends in MWP policies.

\footnotetext{
${ }^{1}$ The pioneering work of Atkinson, Bourguignon and Chiappori (1988) evaluates the redistributive potential of French and British tax-benefit systems by simulating the effects of imposing the French system on the British population and vice versa. De Lathouwer (1996) simulates the effect of imposing the Dutch unemployment benefit scheme on Belgian income distribution data. Bourguignon et al. (1997) use the prototype of the integrated European microsimulation model EUROMOD to simulate common reforms on French, British and Italian data.

${ }^{2}$ Immervoll et al. (2003) follow a similar path and include the possibility to distinguish between elasticities of working hours and elasticities of participation.

${ }^{3}$ Callan et al. estimate an homogeneous labor supply model for four European countries and simulate the different income tax principles applied in the respective countries (separate taxation and splitting systems). Aarberge et al. simulate a common flat rate simplification of the tax system in Norway, Sweden and Italy.

${ }^{4}$ See Pearson and Scarpetta (2000), Bertola (2000), Grad us and Julsing (2000).
} 


\subsection{Social Assistance and Inactivity Traps in Finland, France and Germany}

In the three countries under consideration, social assistance schemes share a common structure which generates potential disincentive to work. Income assistance transfers are indeed computed as a basic minimum income reduced by total household resources among which labor income. In terms of effective marginal tax rates (EMTRs hereafter), households on welfare are then characterized by an implicit $100 \%$ taxation of their earnings. In addition, housing benefits are sharply phased out as earnings increase. ${ }^{5}$

In effect, in all three countries, between 4 and $6 \%$ of the active or potentially active population face EMTRs above $70 \%{ }^{6}$ The concerned population is concentrated in the lower part of the distribution, although some heterogeneity can be found across countries on the exact location of these households in the income distribution. Overall, withdrawal of means-tested transfers is the main cause for high implicit taxation. Most interesting for our analysis is the fact that this feature is common to the three countries we examine while they present wide heterogeneity on other accounts (generosity of social assistance, level of income taxation, etc.). ${ }^{7}$ In all three countries, this phenomena has led national advisors to promote job-enhancing policies.

\section{2 'Making Work Pay' Policies}

Firstly notice that the MWP expression usually encompasses both demand and supply side policies. The former attempt to reduce the cost of hiring low-skilled workers (see Martin and Grubb, 2001) whereas the latter are designed to create incentives to take up low paid work. The present work focuses solely on the second type of policy measures by addressing incentive issues in a pure supply-side framework.

In-work policies have been in place for a long time in the US, with the EITC, and in the UK with the Family Credit and its successors. Canada, Ireland and New Zealand have also had a relatively long experience of such schemes. Since 2000, MWP policies have been spreading rapidly in Europe and some important changes have occured in the UK. The official objective set forth by policy makers is double: (i) to expand employment by increasing work incentives, (ii) to increase income of disadvantaged groups (see Pearson, 2002). There are also country-specific objectives such as the reduction of child poverty in the UK. Such instruments are often seen as more politically acceptable than a rise in social assistance and more desirable given the fear of increasing work disincentives; they are also seen as more efficient than an increase in the minimum wage, which might push up wage rates above the market equilibrium. ${ }^{8}$

Overall, then, a consensus seems to emerge on the need for MWP policies in Europe and on essential aspects of their design (see Duncan, 2003). This view is nevertheless muddied by important concerns regarding (i) the ability of such policy measures to achieve multiple targets and (ii) the fact that there is no unique definition of a MWP policy. In particular, the choice of the unit of assessment may strongly

\footnotetext{
${ }^{5}$ In France however, levels of benefit are relatively higher and withdrawn at a smaller rate than in Finland and Germany.

${ }^{6}$ This characterization of the poverty trap is fully described in a companion paper (Bargain and Orsini, 2004) which compares closely the social assistance systems in the three countries and the distribution of EMTRs.

${ }^{7}$ Finland, France and Germany may diverge with respect to relative generosity of social assistance. German minimum income is relatively more generous than in Finland and in France. Maximum amounts for a lone parent with two children corresponded in 1998 to 9627, 6283 and 5432 EUR in the three respective countries. Aggregate spending varied from 1.3\% of GDP in Germany to $0.6 \%$ in Finland. Notice however that in France, housing benefits contribute significantly to social assistance.

${ }^{8}$ Note however that setting a high minimum wage while subsidising employer costs could be identical in effect to having lower minimum wage and subsidising in-work income. The choice to subsidise employers rather than employees depends on what works best in a particular institutional setting. This in turn depends in particular on which of the two categories is more sensitive to prices. Again, our exercise focuses solely on in-work transfers and incentives.
} 
condition the results. We briefly describe these aspects and the recent choices made in the UK, Belgium and the three countries under consideration.

\subsubsection{Individual versus Family-based Schemes}

A crucial aspect in the design of a MWP scheme is the treatment of the family dimension, and, more precisely, the choice of the unit retained to assess income. Two broad groups of possible schemes are usually encountered, although hybrid measures also exist.

On the one hand, some countries have introduced family-based measures, that is, in-work transfers which depend on household size and which are means-tested on family income. This type of reform, in the fashion of the EITC and the WFTC, is known to be well-targeted to poor working families. However, while the reform unequivocally encourages the participation of single individuals, it is often the case that it discourages second-earners in couples, bringing about a gender bias against the participation of women (see Eissa and Hoynes, 1998, and Blundell et al., 2000, among others). Moreover, the generosity of the reform implies a high taper rate in the phase-out portion of the measure and, hence, large increases in EMTRs and potential disincentives at the intensive margin.

On the other hand, some countries like Belgium have experienced purely individualised measures, conditioned on individual earnings only. Given a similar budgetary cost, this type of measure clearly implies smaller benefits and larger numbers of recipients. Indeed, low-paid individuals in well-off families may well receive some transfers. This policy is thought of as having greater incentive effects than the family-based alternative as (i) it has no discouraging effects on second-earners in a couple, (ii) less generous amounts imply smaller increases in EMTRs in the phase-out region.

\subsubsection{Which Scheme for Which Objective?}

To account for the family dimension or to alternatively retain the individual as the unit of interest has a serious impact on the way reforms contribute to the policy objectives. Targeting low-income families rather than low-wage workers is likely to achieve more redistribution but also risks having more ambiguous incentive effects. While efficiency and redistributive objectives are both quoted to justify large investments in MWP measures, they seem difficult to reconcile within one type of measure. Policy makers may then have to choose one instrument or the other depending on the objective they value the most.

Things are in fact even more intricate. Firstly, a redistributive in-work policy consists fundamentaly of a transfer to the 'working poor'. Yet, some may argue that this group is not the poorest in the poor population. ${ }^{9}$ Secondly, a job-enhancing policy can also be viewed as a way to reduce poverty through increased labor income. An individualized MWP policy should then be considered in this respect and not only for its incentive performances. It must also be noted that single individuals - and mostly lone parents - constitute the largest group of poor households. ${ }^{10}$ This way, a WFTC-type scheme, more generous than an individualized transfer, may then have both redistributive and incentive effects on such vulnerable groups.

\footnotetext{
${ }^{9}$ In this respect, it could be interesting to question 'how rawlsian' should a government be to value an increase in welfare more than in-work transfers. As we shall see, the size of participation elasticities are sufficiently moderate so that this reexamination of the 'old debate' seem legitimate. This is left for future research. See also Immervoll et al. (2003)

${ }^{10}$ According to Buchel, Mertens and Orsini (2003), poverty risk for single mothers is 3 to 5 time larger than the poverty risk for the whole population in the UK and Germany, respectively. In France and Finland as well, lone mothers face a considerably higher poverty rates (around twice the poverty rate of the whole population).
} 
A strong motivation in this paper is to disentangle the various aspects. In the next sections, we suggest an in-depth investigation of the role of family- and individual-based policies in achieving a redistributive objective (poverty reduction) and an incentive objective (social inclusion).

\subsubsection{Recent Trends in the UK and in Belgium}

It this section, we will briefly sketch the UK experience which serves as a benchmark for the family-based policy in our study. We also review the Belgian reform which provides an interesting example of purely individualized policy.

The Working Family Tax Credit (WFTC) introduced in the UK in October 1999 is a more generous variant of the Family Credit (FC). ${ }^{11}$ For instance, the maximum entitlement per year for a lone parent with one child was $£ 3,180$ in 1998 (FC) and $£ 4,160$ in 2001 (WFTC). The credit is a transfer to households with children where at least one of the adults is in paid work (employment or self-employment) for at least 16 hours per week. Eligibility is based on jointly assessed income. Once income reaches a threshold level, the maximum amount is tapered away, at a rate of $55 \%$ on net income (to be compared to $20 \%$ in the EITC system and $50 \%$ in the Self-sufficiency program in Canada); income is assessed after income tax and contributions have been paid; the maximum amount of benefit increases with the number of children, but is paid at the same rate for couples and individuals; a $20 \%$ premium is paid if at least 30 weekly hours are worked (by at least one of the eligible adults) and a $48 \%$ premium per child is added.

No ex-post evaluation of the WFTC reform is yet available and studies rely on ex-ante predictions based on microsimulation softwares and structural models of labor supply. Blundell et al. (2000) find a relatively satisfying distributional effect of the reform while they predict a mitigate effect on employment. ${ }^{12}$ Participation of single women would increase by 34,000 whereas 20,000 married women with employed partners would stop working. Combining other minor changes, the WFTC leads to a small increase in overall participation by just above 27,000 individuals. Consequently, the distributive impact of the reform - rather than the incentive effects - has been appealed to to justify the large cost of the reform. The UK experience illustrates manifestly the difficulty of attaining multiple objectives through a single instrument. The major reform in April 2003 has actually split the WFTC into a refundable Child Tax Credit (CTC) and a Working Tax Credit extended to childless households. While the CTC may well target the UK-specific objective of reducing child poverty, it is not sure that the WTC - officially aimed at supporting low earnings and encouraging labor market participation - will succeed better than the WFTC in achieving both objectives.

In August 2001, the Belgian government introduced a refundable earned income tax credit (Crédit d'impôt sur les bas revenus de l'activité professionnelle). One of the major objectives was to reduce the burden on labor income in general and of taxpayers with low earning capacity in particular. The Belgian tax credit is being implemented on a progressive basis. Eligibility is conditional on working more than 13 hours per week and on having a yearly gross income between 3,850 and 16,680 EUR so that the measure targets workers with an income around the minimum wage (figures refer to the 2003 system and apply to 2002 incomes). The phasing-in is relatively sharp whereas the phase-out segment starts at 12,840 EUR. In 2005, the maximum yearly amount of the benefit should reach 510 EUR. ${ }^{13}$

\footnotetext{
${ }^{11}$ See evaluation of the FC by Duncan and Giles (1996).

${ }^{12}$ See also Duncan and Giles (1998), Dilnot and McCrae (1999) or Gregg et al. (1999).

${ }^{13}$ Orsini (2004) describes and analyses the 2001 Belgian tax reform and finds mitigate labor supply effects related to the individualized tax credit component.
} 


\subsubsection{Recent Policy Changes in Finland, Germany and France}

Neither Finland nor Germany have introduced in work transfers stricto sensu but have focused on income tax allowances and reduction of social contributions for low income. In Finland, an important policy measure was the introduction in 1997 of an earned income allowance on employment income in municipal taxation (see Laine, 2002). Differently from tax credits, allowances are not refundable and the tax saved corresponds to the deduction times the marginal tax rate. In 2004, given an average municipal tax rate of $19.5 \%$, the yearly allowance of 3,550 EUR corresponds to a net gain of $692 \mathrm{EUR}^{14}$

In 2000, the German parliament has adopted a large reform of the income tax system in which tax rates were significantly lowered. The basic personal allowance have also been raised but remains non refundable (see Haan and Steiner, 2004). Hence, the maximum net gain obtained in the first tax bracket should be around 1, 115 EUR in 2005.

In France, a refundable tax credit has been implemented (Prime pour l'Emploi). The PPE is a hybrid measure means-tested at both personal and household levels. Household taxable income must be lower than 11,972 EUR per year (2003 figures) for a single plus additional increments per dependent child. This is doubled for a married couple, which amounts to 3.1 times the labor income of a worker paid at the minimum wage. ${ }^{15}$ Individual taxable income must fall between 3,265 EUR and 23, 207 EUR per year. The maximum amount of credit ( $443 \mathrm{EUR}$ ) is obtained for a full-time and full-year activity paid at the minimum wage rate.

The budget allocated to these recent reforms in Finland, Germany and France is well below the level of transfers implied by the Bristish schemes. An additional motivation for the present study is to question what would happen if these countries dedicated the same budgetary expenses as the UK to MWP transfers.

\section{Simulation of In-work Transfers in Three European Countries}

\subsection{General Description of the Reforms}

The reforms simulated hereafter are in line with the two broad groups of policies surveyed in the previous section. We have opted on the one hand for a working tax credit (WTC) conditionned on family income, and, on the other hand, for an individualized low-wage subsidy (LWS). As described below, simulation choice have continuously tried to balance international comparability and overall coherence in each institutional setting.

The WTC is based on the essential features of the 2001 British WFTC, extended to childless singles and couples. Notice that it does not correspond to the reform implemented in the UK in 2003. In the new British system, the child premium is universalized in a new instrument (the Child Tax Credit). Instead, we have maintained the child element of the WFTC. Policies aimed at recreating significant financial difference between social assistance and paid work must be scaled on family size just as social assistance benefits, in order to tailor the financial gain from taking up work for all household types. ${ }^{16}$ By definition,

\footnotetext{
${ }^{14}$ The net gain in 1998 - our year of interest - was sufficiently small (16 EUR per month) not to interfer dramatically with our simulations.

${ }^{15}$ Bargain (2004b) analyzes the reform and shows that this level is sufficiently high to avoid the discouragement of second earners.

16 Optimally, child increments should be set according to the equivalence scales of national social assistance schemes in order to maintain a sufficient financial gap between inactivity and activity, in particular for households with children. For comparability purposes, we have opted for a homogeneous choice across countries, namely the equivalence scale of the 2001
} 
the wage subsidy is individual and does not account for the family dimension nor for the presence of other incomes.

Both reforms should target those with a significant degree of participation. The LWS is therefore proportional to work duration while WTC eligibility is conditionned on working at least 16 hours (plus a premium given above 30 hours). Even if they both attempt to simultaneously improve work incentives and income redistribution, each reform is meant by construction to emphasize one of the two policy objectives. In this respect, the WTC reform is phased out to increase targeting and reduce budgetary costs; the LWS, set out as an essentially incentive measure, is not phased-out but simply conditionned on the wage rate.

Finally, it is possible to finance the reforms by direct taxation, through, for instance, a change in the income tax rates. This choice would necessarily imply additional labor supply effects which would make difficult the analysis of the effects specific to the MWP policies under study. Consequently, we simply assume alternative ways to let the reforms be financially neutral. One could in particular think of governmental budget reallocation or of an increase in indirect taxation (essentially a proportional tax on consumption) which would not affect neither labor supply behavior nor vertical distribution. More important than revenue-neutrality, reforms must assure to be comparable one with the other. For this purpose, we calibrate the LWS in such a way that it reaches the same real cost - after behavioral responses - as the WTC policy.

\subsection{A Family-based Working Tax Credit}

The rules of the WTC are based on the description given in section 2 for the 2001 WFTC. The formula to compute total household entitlement is as follows:

$$
W T C=B-\max (0 ;(z-\theta) t)
$$

with $B$ the maximum theoretical amount, $\theta$ the threshold or disregard, $t$ the taper rate and $z$ the (jointly assessed) net income of the household. According to 2001 WFTC rules, the taper rate $t$ equals $55 \%$; this corresponds roughly to $37 \%$ on gross income in the UK but to different percentages across the countries we examine. The maximum amount of benefit $B$ is $74.6 \mathrm{EUR} /$ week for a childless household. ${ }^{17}$ Maximum entitlement does not depend on the number of adults but increases by $49 \%$ per dependent child. The threshold $\theta$ amounts to 128.3 EUR per week. ${ }^{18}$ Other features of the WFTC are taken into account. ${ }^{19}$

In the assessment of family income $z$, all main sources of income are included net of taxes and social security contributions. In the UK, the income assessment for the WFTC is the same as for social assistance (Income Support) so that all family benefits are included with the exception of the Child Benefit, the Maternity Benefit and the Statutory Maternity Pay (plus small UK-specific disregards). In a similar way, WTC assessment is modelled along the lines of existing social assistance benefits and the universal child benefits (as well as some specific disregards) are excluded from the means-test.

\footnotetext{
WFTC.

${ }^{17}$ This figure corresponds to the $£ 54$ /week in the 2001 WF TC rules, which correspond to $£ 50.6$ in 1998 prices (inflation of $6.8 \%$ over the three year period).

${ }^{18}$ This figure corresponds to $£ 92.9$ /week in 2001 which gives $£ 87$ in 1998 prices. For $B$ and $\theta$, absolute amounts are taken from the British reform and simply converted using 1998 exchange rates (0.67833£/EUR). Alternatively, we could have chosen relative amounts computed as a function of a national reference such as the average equivalized income. Results would then possibly be sensitive to the reference figure chosen.

${ }^{19}$ This includes the childcare credit and a further condition that the family should have less than $£ 8000$ worth of capital. These are not modelled since information on childcare is not reliable and wealth is ill-defined in the data.
} 
A sensitive issue in modelling WTC concerns the way it interacts with the rest of the system. As in the UK, WTC is not itself taxable but enters income assessment of minimum income schemes. ${ }^{20}$ Other features of the reform are modelled as consistently as possible across countries. ${ }^{21}$

\subsection{An Individual Wage Subsidy}

The LWS reform consists of increasing individual labor income $y=w h$ by a percentage $A .^{22}$ The wage subsidy decreases if the wage rate is larger than a lower bound $\alpha W$ until it falls to zero at an upper bound $\beta W$. Both bounds are expressed in function of a reference wage $W$. There are no official wage floors - a natural choice for $W$ - in Germany and Finland. Instead, we opt for the $10 \%$ cut-point of the wage distribution of each country, which corresponds to 6.09 EUR per hour for France (close to the 1998 French minimum wage), 6.79 for Finland and 7.42 for Germany. For comparative purposes, the others parameters are simply fixed uniformly across countries $(\alpha=1$ and $\beta=1.4) .{ }^{23}$

The supplement factor $A$ is country-specific and calibrated iteratively in order to reach the same budgetary cost for both WTC and LWS reforms. After calibration, we find $A=12 \%$ for Finland, $20.5 \%$ for France and $13 \%$ for Germany. The formula to compute the level of the LWS is written as follows:

$$
\begin{aligned}
& L W S=A y \quad \text { if } w / W \leq \alpha \\
& L W S=K A y \quad \text { if } w / W \in[\alpha, \beta]
\end{aligned}
$$

with $K=\frac{(\beta-w / W)}{\beta-\alpha} \in[0,1]$.

\subsection{Impact of the Reforms on Budget Curves}

We now look at hypothetical budget constraints in Figure 1 to comment on the effects of the reform on the systems in force. It must be stressed that these examples are merely illustrative and we shall not generalize them too widely on this basis.

On the left hand-side, we illustrate the budget constraint of a single individual (here for Finland) assumed to be employed full year. ${ }^{24}$ The horizontal axis represents gross earnings while disposable income is on the vertical axis. It is assumed that the first half of the horizontal axis corresponds to a linear increase in weekly hours of work from 0 to 40 while the second half corresponds to a linear increase in the hourly wage from 6 to 12 EUR. This way, the amount of wage supplement $A w h$ increases linearly with working time (phasing-in) at a flat rate $A w$ so that the slope of the budget curve gets steeper. After hitting 40 hours, the wage rate increases and the benefit starts to decrease as soon as it exceeds the reference wage (6.79 EUR for Finland).

The amount of WTC is depicted at the bottom of the graph and the 16 hours threshold is particularly evident as it marks the eligibility, as well as the discontinuity for the 30 hours premium. Looking at the

\footnotetext{
${ }^{20}$ Note that in Germany, the level of social assistance impacts in turn on the computation of housing benefits.

${ }^{21}$ Contrary to the situation in the UK, WTC does not condition housing benefit directly. This choice is made for comparability purposes since housing benefits condition in turm the computation of social assistance in Finland and France. See Bargain and Orsini (2004).

${ }^{22}$ It is assumed that authorities are able to collect information relative to work duration or, equivalently hourly wage rates, both in a reliable way and with no additional administrative cost.

${ }^{23}$ Note, however, that for a true policy design, these parameters could be chosen optimally to adapt the reform to the wage distribution as described earlier. Note also that the individual tax credit applied in France in 2001 was also officially phased out between 1 and 1.4 time the minimum hourly wage while the same order of magnitude applied in the individual Belgian reform.

${ }^{24}$ Budget curves under both reforms for all three countries and for all typical household types (single, single plus children, one- and two-earner couples with children) are available upon request.
} 
budget contraints, it appears that the WTC creates strong gain to work while the new financial incentive coming from the LWS seem more modest. In both cases, reforms unambiguously enhance the probability of participation for single individuals or lone parents. ${ }^{25}$

On the right hand-side, we represent a similar graph for a couple (here for Germany). The first half of the horizontal axis corresponds here to a linear increase in weekly hours of work from 0 to 40 for the first-earner while the second half corresponds to a linear increase in weekly hours of work from 0 to 40 for the second-earner. The difference between the pre-reform disposable income and the disposable income with WTC corresponds to the net gain from the WTC, depicted at the bottom of the graph (this is simply the difference between the two budget curves). This gain turns out to be much smaller than the amount of the transfer, which is due to the fact that the WTC enters income assessment for social assistance. ${ }^{26}$ This effect occurs in all countries and is maximum in the case of Germany, due to a more generous safety net. It appears that the maximum net gains are in a range between 10,000 and 15,000 EUR instead of between the 5,000-10,000 EUR as initially targeted by the reform. ${ }^{27}$

In all countries however, the WTC recreates a significant financial difference between non-participation and full-time activity for the first-earner. The opposite actually occurs for the second-earner. As the latter increases her labor supply, the amount of WTC received through the pay of the first-earner is phased out. Two indifference curves are represented on this part of the graph. The one below is tangent to the budget curve in the pre-reform situation at a point where the second-earner is in activity (part-time here). The upper curve leads however to a corner solution, meaning that the reform would induce the second-earner to move out of work.

\section{Framework Conditions}

As recalled in the introduction, it appears crucial to review the initial conditions which determine to which extent each policy can achieve its objectives. An important aspect is the way a reform interacts with the existing system, as previously shown in the case of the WTC. ${ }^{28}$ Other factors of great policy relevance are examined hereafter, including the shape of wage and income distributions in the country and the size of labor supply elasticities.

\footnotetext{
${ }^{25}$ The changes in the slopes of the budget curves also show that the LWS would lead to a slight decrease in the level of EMTRs. Recall that since the transfer decreases as the wage rate - and not the working time - increases, there are no phasing-out with this reform. Conversely, the WTC is tapered away at a high rate so that EMTRs increase substantially. See Bargain and Orsini (2004) for an in-depth analysis.

${ }^{26} \mathrm{It}$ is not relevant to represent the LWS here as it does interact with the system, clearly coming as a new layer on top of all existing instruments.

${ }^{27}$ This effect did not appear in the previous example on a Finnish single individual (left hand side graph) as his eligibility ceases at about the same point as where eligibility to WTC begins (the 16 hour threshold).

${ }^{28}$ Pearson (2002) and Pearson and Scarpetta (2000) state that if tax rates are already high, the phasing-out of MWP payments may raise EMTRs to unacceptably high levels. We argue that not only income taxation but all means-tested instruments must be systematically considered on that account, as done throughout the budget curve analysis above. In complement, Bargain and Orsini (2004) analyse how the distribution of EMTRs is affected by the simulated reforms in each country. Notice that the level of EMTRs is an aspect on which we do not focus much. In fact, we follow here the bulk of the recent literature on labor supply so that our estimation strategy captures mainly participation decisions (the extensive margin).
} 
Single (Finland)

(wage $=6$ euros/hour up to full time, linear increase beyond)

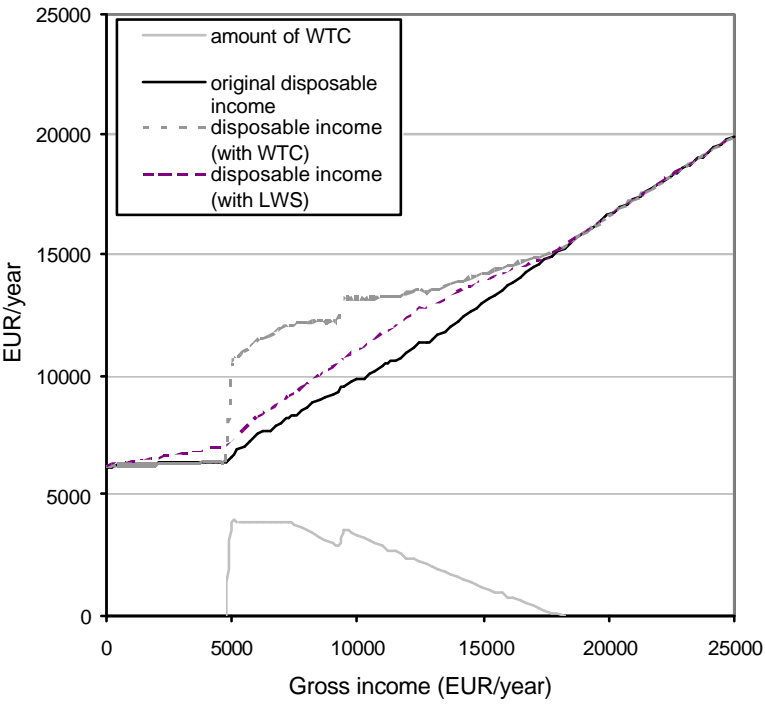

Note: gross income increases with working hours up to full time (40h/week) then with hourly wage (from 6 to $12 \mathrm{EUR} / \mathrm{h}$ )

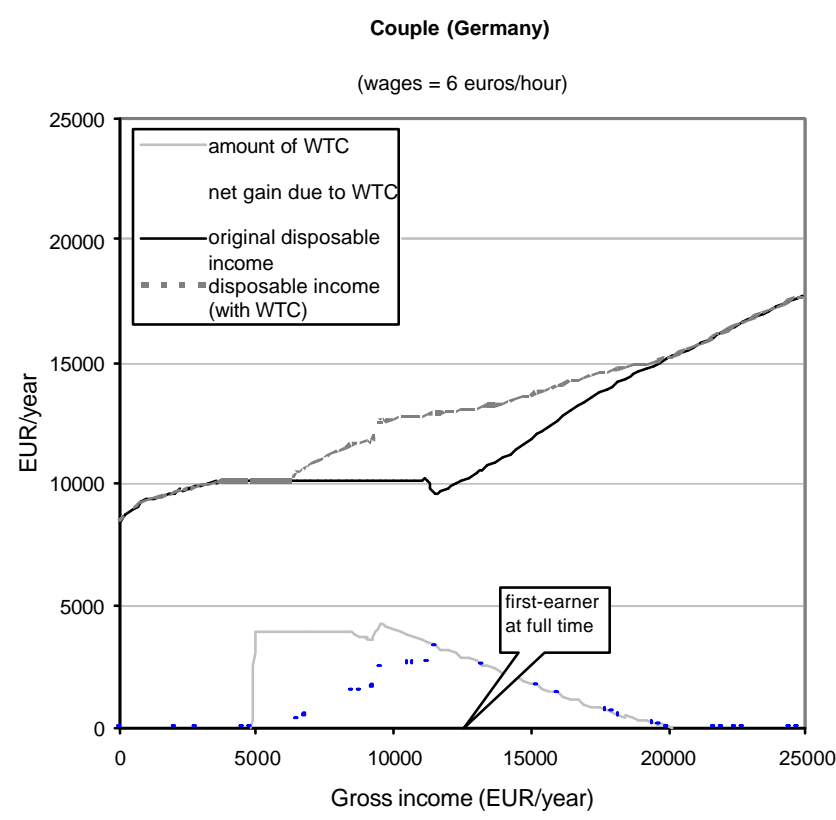

Note: household gross income increases with the first earner's labor income (first half, up to 12,500 EUR) then with the second earner's labor income (second half, up to 25,000 EUR)

Figure 1: Budget Curves

\subsection{Distribution of Working Hours, Earnings and Wage Rates}

Table 1 details the participation rate of each country's population, and more precisely, the proportion of households where at least one member works at least 16 hours a week, that is, the proportion of households potentially entitled to the WTC. ${ }^{29}$ While actual eligibility also depends on household income, large differences in participation rates across countries should contribute to a larger number of recipients in Finland.

Table 1: Participation Rate across Countries

\begin{tabular}{lccc}
\hline \hline & France & Germany & Finland \\
\cline { 2 - 4 } household in work & $59,4 \%$ & $51,4 \%$ & $79,2 \%$ \\
household with $\mathrm{h}>15 \mathrm{~h} /$ week & $58,4 \%$ & $50,6 \%$ & $78,1 \%$ \\
\hline Source: authors' computation. & & &
\end{tabular}

\footnotetext{
${ }^{29}$ Figures may seem unduly small as they are computed as a proportion of the whole population of each country (and not on the selected sample used for labor supply estimations).
} 

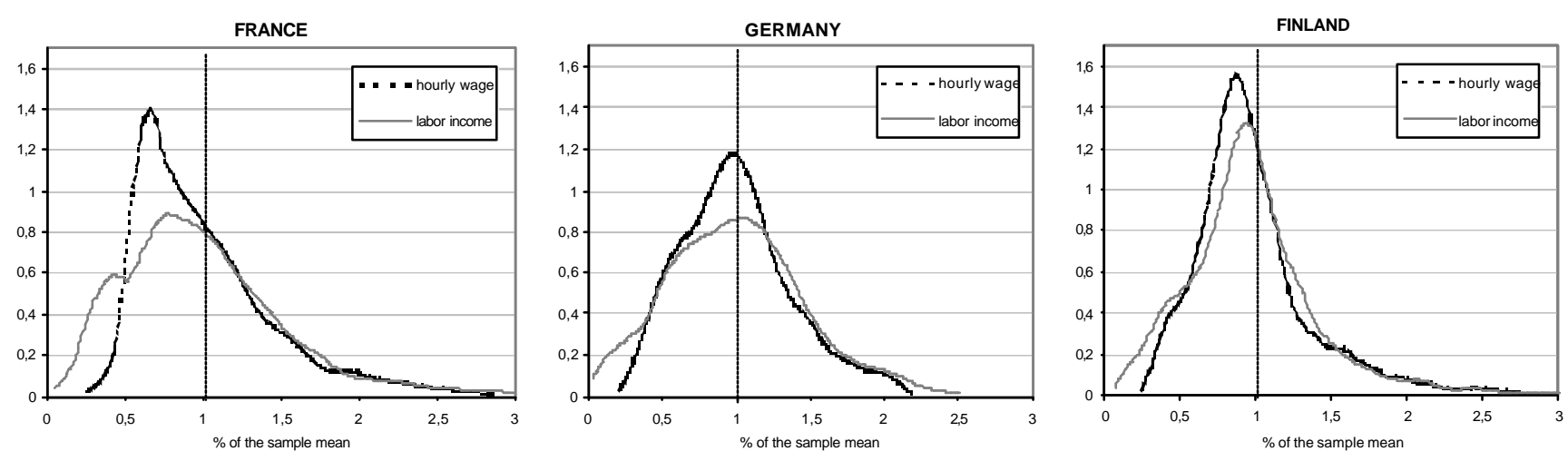

Figure 2: Distribution of Hourly Wage Rate and Labor Income for Active Women

The distributions of females' wage rates and labor incomes, represented in Figure 2, are also important to explain the impact of the reforms. ${ }^{30}$ The Figure reveals that for female workers, the distribution of wage rates in Finland is slightly more concentrated than in France and in France than in Germany. This observation seems in line with the literature on wage inequalities which usually places France between Scandinavian countries and Finland on one side and the UK and Germany on the other. Cross-country differences in the concentration of incomes are more marked and in particular, the distributions become much more unequal in France and Germany compared to Finland..$^{31}$ Finally, the presence of a wage floor in France induces important asymmetries in the distributions - especially in the wage rate - compared to the other countries.

The distribution of incomes is naturally what matters for the design of the WTC. In particular, it is remarkable that the asymmetric distribution in France implies a larger density of workers to be found in a lower income range, as compared to Finland. This way, it is likely that a larger proportion of households will be found in the flat segment of the WTC in France, whereas a larger density of the population in the phase-out region or above in Finland. Other things being equal, this will imply smaller average amounts of WTC in Finland and, to some extent, partially offset the differences in theoretical eligibility as explained above by the differences in participation rates.

In the case of the LWS policy, the differences in wage rate distributions must be considered. The important feature here is that the eligibility zone is adapted to the wage distribution insofar as LWS decreases with the wage rate from the first decile cut-point $W$ to exhaust at $1.4 W$. The concentration in the region from $W$ to $1.4 W$ then conditions the number of eligibile individuals. Graphs show that the modes in France and Finland are located in lower range of values (compared to the mean wage). ${ }^{32}$ Higher concentration in Finland implies relatively more eligible individuals, ceteris paribus.

\footnotetext{
${ }^{30}$ Similar graphs for men are not provided as differences in concentrations are less significant, either across countries or between the distribution of wage rates and the distribution of labor incomes.

${ }^{31}$ This is explained by overall larger wage-elasticities in these countries. A positive wage-elasticity indeed mean that labor supply increases with the wage rate so that the distribution of labor income is more unequal than the distribution of skills. This effect is all the larger as elasticities are large (see Stern, 1986). Naturally, more precise statement would imply to look not only at the mean values but also at the distribution of elasticities in the sample and at the evolution of the mean elasticity across the different levels of labor supply.

${ }^{32}$ The same feature applies for the male wage, not represented here.
} 


\subsection{Labor Supply Elasticities}

A key issue in determining the impact of reforms is the elasticity of labor supply to exogenous changes in budget constraints. We simply look at own wage-elasticities to provide an order of magnitude of the potential labor supply responsiveness across countries.

To model labor supply, we rely on the recently developed technique based on a structural unitary model with discrete work hours. Following many examples in the literature, we focus solely on female labor supply. This choice is usually motivated by the fact that female participation is lower and working hour are more variable than men's, as female work is often regarded as a second source of earnings. ${ }^{33}$ At the same time, male labor supply is known to be very inelastic to moderately sized exogenous changes in the budget constraint. ${ }^{34}$ An option would be to model only participation decisions for men. Yet, in the countries we examine, the number of inactive men remaining after the selection process has revealed too small to estimate a robust model of joint decisions in the household. ${ }^{35}$ Consequently, we simply treat male labor supply as fixed at observed values. ${ }^{36}$

Female labor supply is supposed to vary discretely between full-time, part-time and non-participation. This strategy incorporates explicitly the evidence that most salary workers are constrained to choose among a limited set of options due to social/institutional norms and demand-side rigidities. Concentrations of hours around part-time and full-time work is evident in the distributions of hours (see Figure 4 in the Appendices). Self-employed workers may have more freedom to choose in a continuous range of hours but are not included in our selection. Note that one of the most prominent aspects of modern literature on labor supply, as surveyed by Heckman (1993), is the fact that labor supply responsiveness is much larger at the extensive margin. ${ }^{37}$ In this respect, our modelling strategy focuses mainly on participation decisions, even though the possible variations in hours are partially captured by the part-time option. The model, and the estimation results are described in the Appendices.

Estimates are used to compute elasticities. Evaluating elasticities at the sample mean is not very informative - in a highly nonlinear model like ours - on the consequence of wage changes in a heterogeneous population. Instead, we compute wage-elasticities numerically and averaged over the whole sample. To do so, we increase female wage rates uniformly by $1 \%$ and $10 \%$ and simulate in each case the subsequent changes in average work duration and in the participation rate. ${ }^{38}$

\footnotetext{
${ }^{33}$ See Laroque and Salanié (2002) for a recent comprehensive discussion.

${ }^{34}$ This has been justified on sociological grounds and proved extensively in labor supply literature (see surveys from Pencavel, 1986, or more recently Blundell and MaCurdy, 2000).

${ }^{35}$ In addition, male inactivity is known to be mostly explained by demand-side rationing in those countries.

${ }^{36}$ Even if one does not believe in the so-called second-earner model of the household, it seems reasonable to think that the suggested reforms should not have any negative impact on the participation of men in couple; they should not have any positive impact either as the selected sample contains very few inactive couples. The approach is slightly more detrimental if we consider single men as some inactive ones may be encouraged to take up a job with the reforms; however, inactive single men are under-representated in most surveys and disappear almost completely after the selection process described in the Appendices. To capture the impact of in-work policies on this sub-population, specific datasets are required. Gurgand and Margolis (1998) make use of a survey on minimum income recipients in France.

${ }^{37}$ The most recent and convincing proofs are precisely provided by natural experiments related to in-work transfers. For instance, Meyer (2003) studies the changes in the Earned Income Tax Credit in the US between 1990 and 1996 . He shows that nearly all of the labor supply adjustment by single mothers in response to these changes occured at the extensive margin. The weakness of adjustment in working hours is merely explained by behaviors and not connected to an explanation in term of rationing of worked hours (the US labor market presenting a much more continuous distribution of work hours than in continental Europe).

${ }^{38}$ Transition frequencies are the means over 200 simulated transitions. Each transition is obtained by calibration of the stochastic part of the utility at each hour choice in order to obtain a perfect match between observed and predicted hours
} 
Table 2: Change in Female Average Working Hours

\begin{tabular}{cccccc}
\hline \hline \multirow{2}{*}{ country } & \multicolumn{2}{c}{ women in couples } & & \multicolumn{2}{c}{ single women } \\
& \multicolumn{2}{c}{ wage $+1 \%$} & wage $+10 \%$ & & \multicolumn{2}{c}{ wage $+1 \%$} & wage $+10 \%$ \\
\cline { 2 - 3 } \cline { 5 - 6 } France & $0.62 \%$ & $5.91 \%$ & & $0.12 \%$ & $1.09 \%$ \\
& {$[0.54 ; 0.74]$} & {$[5.2 ; 6.5]$} & & {$[0.07 ; 0.16]$} & {$[0.8 ; 1.4]$} \\
Finland & $0.15 \%$ & $1.42 \%$ & & $0.28 \%$ & $2.66 \%$ \\
& {$[0.11 ; 0.19]$} & {$[1.0 ; 1.8]$} & & {$[0.19 ; 0.39]$} & {$[1.8 ; 3.4]$} \\
Germany & $0.40 \%$ & $3.77 \%$ & & $0.16 \%$ & $1.44 \%$ \\
& {$[0.32 ; 0.47]$} & {$[3.1 ; 4.5]$} & & {$[0.10 ; 0.22]$} & {$[0.9 ; 1.8]$} \\
\hline Elasticities are computed using averaged simulated transitions; figures in brackets give a bootstrapped $90 \%$ confidence
\end{tabular}

interval of the elasticity

Table 3: Change in Female Participation Rate

\begin{tabular}{cccccc}
\hline \hline \multirow{3}{*}{ country } & \multicolumn{2}{c}{ women in couples } & & \multicolumn{2}{c}{ single women } \\
& \multicolumn{2}{c}{ wage $+1 \%$} & wage $+10 \%$ & & \multicolumn{2}{c}{ wage $+1 \%$} & wage $+10 \%$ \\
\cline { 2 - 3 } \cline { 5 - 6 } France & $0.55 \%$ & $5.20 \%$ & & $0.07 \%$ & $0.61 \%$ \\
& {$[0.48 ; 0.65]$} & {$[4.6 ; 5.8]$} & & {$[0.03 ; 0.10]$} & {$[0.4 ; 0.7]$} \\
Finland & $0.15 \%$ & $1.40 \%$ & & $0.27 \%$ & $2.61 \%$ \\
& {$[0.11 ; 0.19]$} & {$[1.0 ; 1.7]$} & & {$[0.19 ; 0.39]$} & {$[1.8 ; 3.3]$} \\
Germany & $0.33 \%$ & $3.22 \%$ & & $0.13 \%$ & $1.19 \%$ \\
& {$[0.25 ; 0.39]$} & {$[2.7 ; 3.8]$} & & {$[0.07 ; 0.19]$} & {$[0.8 ; 1.5]$} \\
\hline Elasticities are computed using averaged simulated transitions; figures in brackets give a bootstrapped $90 \%$ confidence
\end{tabular}

Elasticities are computed
interval of the elasticity 
Elasticities presented in Tables 2 and 3 are in line with recent labor supply literature (see Blundell and MaCurdy, 2000). Significant differences across country are not surprising, as we suggest in the following review of literature. Note that the figures presented here are only average values while it may be interesting to compare the distribution. By construction, elasticities of working hours implicitly account for participation effects in the present paper, which may not be the case in all the studies quoted below.

For France, the values we obtain compare well with the order of magnitude of recent findings, even if slightly higher, which may simply be due to different data selection hypotheses. Bargain (2004a), indeed, focuses on married/cohabiting females with working partners only. This way, matching aspects between partners imply a higher participation level for these women hence lower elasticities of hours (around 0.3). Choné et al. (2003) study only couples with at least one child under the age of seven and find participation elasticities around 0.3 (when the censorship effect of the minimum wage is not accounted for).

In Germany, results are in the range of recent estimates provided by Bonin, Kempe and Schneider (2002), Haan (2004), Steiner and Wrohlich (2003) and Haan and Steiner (2004). All these studies rely on the GSOEP (2000 wave in the first study, 2001 in the second and third studies and 2002 in the last one). Bonin et al. (2002) find own wage-elasticities of 0.27 with respect to working hours and 0.20 with respect to participation for women in couples while Haan (2003) finds 0.32 and 0.13 respectively. Our elasticities are slightly higher probably because we do not account for the joint decision in couples. Indeed, when husbands' labor supply is assumed fixed, Haan and Steiner (2004) find female elasticities of working hours very close to ours (0.39); the results also match very well for single women as they find elasticities of 0.13 . As in all related studies on Germany, elasticities are found markedly smaller for East German females.

Smaller wage-elasticities for married women in Finland coincide with a higher proportion of women working full-time in this country. Yet, there are few st udies related to labor supply estimations for Finland. For the year 1987 (before the Finnish recession), Ilmakunnas (1992) considers only working women in couple and finds uncompensated wage-elasticities in a range between 0.09 and 0.11 . Elasticities found by Kuismanen (1997) are even smaller. In both cases, it is difficult to compare these results with ours, as participation effects do not seem to be accounted for. Kuismanen (2000) finds very small responses to important changes in the tax system and Laine (2002) provides difference-in-difference estimations of the impact of the 1996-2001 reforms, finding very moderate effects. Overall, it seems that labor supply responsiveness is extremely small in Finland. Larger elasticities for singles than for married women remain surprising however and require further investigation.

Our approach could fruitfully be compared to the strategy of Spadaro (2004) who acknowledges the lack of consensus in the literature regarding the size of elasticities and simply postulates different levels of labor supply responsiveness to analyze the impact of tax reforms on social welfare. In the present paper, we rely more traditionally on the econometric approach despite the well-known limitations (see the Appendices). This approach enables us to capture discrepancies in labor supply sensitivity across countries which turn out to be prominent in explaining the difference in results for an identical tax reform. Still, an interesting complementary exercise, left for future research, would consists in assuming identical elasticities across countries in order to capture what relates specifically to institutional factors (existing tax-benefit systems, wage/income structures etc.) in explaining cross-country discrepancies in the effects

for the pre-reform situation. Confidence intervals for each transition cell and summary measure are simulated by drawing 200 times from the estimated asymptotic distribution of the parameter estimates and for each of those parameter draws, applying the calibration method to build transition matrices. The same technique is applied to simulate the labor supply effects of a reform. See Bargain (2004a) for a more detailed description. 
of each reform. ${ }^{39}$

\section{Tax Reform Analysis}

\subsection{Tax Reform Analysis without Behavioral Responses}

'First-round' analysis consists simply in assessing the cost and targeting of each reform when no behavioral response is taken into account. This is usually done by static microsimulations and in this study, we make use of the European integrated tax-benefit model EUROMOD described in the Appendices.

\subsubsection{Cost and Distributional Analysis}

The static analysis of the WTC is summarized in Table 4. The relative cost of the reform, as a proportion of the country's total 1998 GDP, allows for straightforward cross-country comparison. It appears that the apparent cost is slightly smaller in Germany $(0.36 \%$ of GDP) than in France or Finland (around $0.40 \%$ of GDP). In absolute terms, the cost of 5.8 billion EUR in France and 7.6 billion in Germany can be compared to the $£ 5$ billion spent in 2001 in the UK on the WFTC (7.3 billion EUR).

As expected in the discussion on framework conditions, the number of recipients is larger in Finland (10.6\% of the households) than in France (10.1\%) and in Germany (9\%). Results are nevertheless reasonably comparable across countries. The difference between France and Finland is not as large as could be expected when looking at participation rates only. As mentioned above, part of the difference is offset by the fact that earnings are concentrated in higher ranges of income in Finland, which also explains the somewhat lower level of the average benefit (39 EUR per week versus 43 in Germany and 49 in France). As seen in Figure 3, the reform targets the first half of the distribution of equivalized incomes, just as in the UK. The first decile receives less than the three next deciles as it is composed mainly of inactive households which are not targeted by the reform.

The net cost (i.e. total variation in disposable income) is naturally lower than the apparent cost (total expenditure on the WTC by the government) as the introduction of the WTC partially crowds out spending on social assistance. For instance, in France, the difference between apparent (5.86 billion EUR) and net costs (5.741) is explained for $97 \%$ by the subsequent decrease in social assistance (RMI/API). The difference between apparent and net costs is especially large in Germany (around 20\%), certainly due to the generosity of the German minimum income scheme. A close to budget curves in Bargain and Orsini (2004) reveals that working 16 hours at minimum wage in France and in Finland is sufficient to exit the segment of income assistance while the same does not hold for Germany.

The static analysis of the LWS is also summarized in Table 4. Note that there is no difference between apparent and net costs as the LWS does not interact with the rest of the system. The parameters of the reform have been calibrated so that post-response costs of both reforms are as close as possible. As we shall show below, a net decrease in labor supply in France following the WTC implies a relatively larger post-response cost for this reform, and, hence, for the LWS as well; moreover, important positive

\footnotetext{
${ }^{39}$ Notice that in the bootstrapped confidence intervals provided in Figures 2 and 3 , the bounds are close enough to perform some sensitivity analysis. In the case of married women for instance, upper bound of the confidence interval for Germany (resp. Finland) is fairly close to the lower bound for France (resp. Germany). At the same time, the upper level of response to the WTC reform in Germany does not reach the lower level in France, as shall be seen below. This clearly means that differences in labor supply preferences explain only part of the cross-country differences in the effects of the reforms.
} 
Table 4: Descriptive Statistics for the Reforms

\begin{tabular}{|c|c|c|c|c|c|c|c|}
\hline & & & WTC & & & LWS & \\
\hline & & France & Germany & Finland & France & Germany & Finland \\
\hline $\begin{array}{l}\text { apparent cost } \\
\text { net cost }\end{array}$ & (billion euros/year) & $\begin{array}{l}5.859 \\
5.741\end{array}$ & $\begin{array}{l}7.662 \\
6.221\end{array}$ & $\begin{array}{l}0.506 \\
0.492\end{array}$ & 8.206 & 7.476 & 0.545 \\
\hline $\begin{array}{l}\text { apparent cost } \\
\text { net cost }\end{array}$ & (in \% of 1998 total GDP) & $\begin{array}{l}0.404 \% \\
0.395 \%\end{array}$ & $\begin{array}{l}0.356 \% \\
0.289 \%\end{array}$ & $\begin{array}{l}0.394 \% \\
0.383 \%\end{array}$ & $0.571 \%$ & $0.350 \%$ & $0.406 \%$ \\
\hline recipients & $\begin{array}{l}\text { (nb of hh) } \\
\text { (\% of total population) }\end{array}$ & $\begin{array}{c}2,316,233 \\
10.1 \%\end{array}$ & $\begin{array}{c}3,443,208 \\
9.0 \%\end{array}$ & $\begin{array}{c}248,663 \\
10.6 \%\end{array}$ & $\begin{array}{c}5,277,893 \\
22.9 \%\end{array}$ & $\begin{array}{c}6,334,906 \\
16.6 \%\end{array}$ & $\begin{array}{r}538,521 \\
22.9 \%\end{array}$ \\
\hline $\begin{array}{l}\text { net average amount } \\
\text { net max. amount }\end{array}$ & $\begin{array}{l}\text { (euros/week) } \\
\text { (euros/week) }\end{array}$ & $\begin{array}{r}49 \\
205\end{array}$ & $\begin{array}{c}43 \\
149\end{array}$ & $\begin{array}{c}39 \\
248\end{array}$ & $\begin{array}{c}30 \\
111\end{array}$ & $\begin{array}{l}23 \\
81\end{array}$ & $\begin{array}{l}19 \\
83\end{array}$ \\
\hline
\end{tabular}

Source: authors' computations using EUROMOD
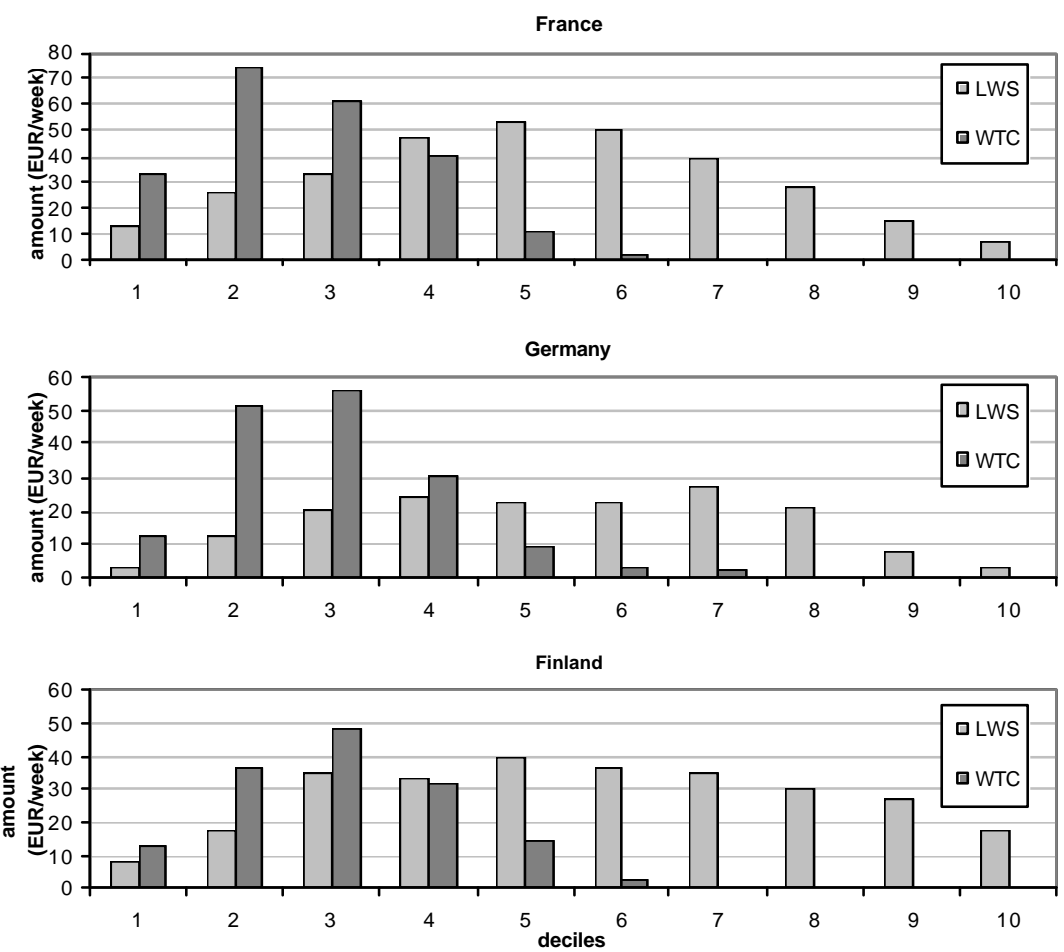

Figure 3: Average Amount of Transfer per Decile of Adult Equivalent Disposable Income 
responses to the LWS imply an even larger pre-response cost for the LWS in France. This mainly explains the important differences (across countries and across reforms) in the cost and in the number of recipients.

As discussed in the review of MWP policies, the individual LWS reform is by nature less targeted than the family-based WTC. In effect, the number of recipient households is twice as large as with the WTC. As seen in Figure 3, the policy measure attains individuals in all income deciles as low-wage individuals can be found in richer families.

Furthermore, it appears that the impact of the LWS depends on structural factors as discussed previously. As shown in Figure 2, hourly wages are rather concentrated at the lower end of the distribution in France and Finland, which explains a relatively larger number of eligible individuals $(22.9 \%$ of the households contain at least one eligible individual). Table 4 presents average amounts per household (and not per individual); differences between France and Finland simply result from a much higher total cost in France for an identical proportion of recipients in both countries. Germany stands inbetween as both total cost and total number of recipients are smaller (as seen above, the latter is due to a more dispersed wage distribution). ${ }^{40}$

\subsubsection{Characterization of Potential Effects on Hours and Participation}

The potential impact of the reforms on working hours can be characterized by the variations in the distribution of EMTRs. ${ }^{41}$ With the WTC, EMTRs should increase in the phase-out range as the amount of transfer decreases with increments in gross income. The increase does not exactly corresponds to the $55 \%$ taper rate as the latter applies to the income concept $z$ (labor income net of tax and social security contributions plus some benefits) rather than to gross earnings. This way, for a given additional Euro of gross income, the corresponding variation $d z$ should be smaller in Finland and Germany since taxes and social contributions are higher in those countries than in France; hence the increase in the EMTR is smaller in both of these countries. The impact of the LWS reform on the EMTR is simply a decrease of $K A$. Numerical simulations of EMTR confirm this analysis. With the introduction of the WTC, EMTRs increase substantially for deciles targeted by the reforms and the rise is more important in France, given the initial lower level of EMTR. The LWS reform shifts EMTRs downwards along the whole income distribution. Yet, the strongest reduction occurs between the 2 nd and the 4 th decile as the subsidy mostly targets very low wages. ${ }^{42}$

The female labor supply modeling strategy retained in this paper focuses mainly on participation decisions, for which the relevant aspect is the net financial gain to work. These gains correspond simply to the relative increase in household disposable income when the woman works full or part-time as compared to remaining inactive. To compute the gains, we use wage rates taken from the data or predicted by traditional econometric means for inactive females.

Larger amounts of transfer through a well targeted WTC naturally lead to a larger increase in financial gains to work for single women. This is particularly striking as regards the gain of working part-time, which rises from 47 to $79 \%$ in France, 67 to $91 \%$ in Germany and 56 to $81 \%$ in Finland. The increase

\footnotetext{
${ }^{40} \mathrm{~A}$ detailed analysis per household typologies is provided in Bargain and Orsini (2004). Unlike the WTC, the size of the average subsidy turns out to be almost constant across household types. Couples are slightly above the average simply because there can be more than one eligible individual per couple.

${ }^{41}$ In principle, EMTRs could be computed analytically as one minus the first derivative of the budget constraint. However, the complexity of the tax-benefit system forces us to rely on a numerical approximation. For a description of the technique at use, see Bourguignon (1997), Immervoll (2002) and Bargain and Orsini (2004).

${ }^{42}$ The detailed impact of the reforms on the distributions of EMTRs and financial gains to work is presented in Bargain and Orsini (2004).
} 
is much smaller with the LWS (only 2 or 3 percentage points). The average gain of working full-time increases by 7 percentage points in Finland and by more than 10 points in Germany and France with the WTC; it increases only by half of this when the LWS is introduced. Similarly, the proportion of very low gains (less than 40\%) decreases substantially when the WTC is introduced, and this for all three countries. ${ }^{43}$

However, for married women the picture is completely different. First, it is noticeable and expected that the gain is much smaller than for single individuals; this is especially the case in France and Germany where the earnings of the second-earner are taxed away at the marginal tax rate of the first earner, a consequence of the joint income taxation system. The same holds for the WTC for which income is jointly assessed at the household level. As a result, additional earnings by wives may lead to a loss in WTC entitlement for their working partners, as seen in the budget curve analysis. The gain of working full time thus shifts from 58 to $50 \%$ in France, 58 to $53 \%$ in Germany and 65 to $61 \%$ in Finland. In addition, the proportion of small gains associated to working full-time (less than $30 \%$ ) increases drastically in France (from $9.5 \%$ to $20 \%$ of the selected women) and more moderately in Germany and Finland (from 17 to $23 \%$ and from 7.7 to $10.8 \%$ respectively). The LWS slightly improves average gains of working (especially full-time) and reduces the proportion of small gains, especially in France and Germany. ${ }^{4}$

\subsection{Tax Reform Analysis with Behavioral Adjustments}

\subsubsection{Labor Supply Responses}

Labor supply responses to the WTC are presented in Table 5. The intuition from the analysis of financial gains of work are confirmed by the fact that more than $1.5 \%$ of the sample of single women in Germany and $1.8 \%$ in Finland are encouraged to enter the labor market. Even though the increase in the financial gains is of comparable magnitude across countries, results turn out to be much larger in Germany and Finland than in France due to the following two reasons. Firstly, the pre-reform participation rate is comparatively much lower in Germany than in France in our selection of singles (see Appendices). Secondly, the participation elasticities are substantially larger, especially in Finland (see Table 3).

Our previous analysis of the financial gain of work also confirms that the WTC introduces a bias towards the participation of second-earners, mostly the wives. In effect, the simulations confirm that a substantial number of married women whose partner works would leave the labor market. This effect is particularly strong in France, with $4.35 \%$ of the selected women in couples leaving their job. This comes as no surprise since the gains of working decrease dramatically in this country while the elasticity of married women is the highest. The proportion of women potentially discouraged to work is smaller in Germany $(2.79 \%)$ and Finland (1.34\%). In all countries, the associated earnings loss is partially compensated by an increased tax credit on the husband's earnings while additional utility is theoretically drawn from more leisure (or domestic production, not modelled as such in the present setting).

Overall, the disincentive effect for married women prevails so that the net effect on employment is negative in all three countries and proportionnally larger in France (a net $3 \%$ of the population would withdraw from the labor market) than in Germany and Finland (respectively 0.78 and $0.14 \%$ ). Confidence intervals displayed in Table 5 are small enough to confirm the robustness of these results.

\footnotetext{
${ }^{43}$ For France, a clear stochastic dominance of the situation with WTC on the system with LWS (and of the latter on the pre-reform situation) can be shown graphically, for gains up to 100\%. In the two other countries, the same is true for all gains but less marked. See Bargain (2004a).

${ }^{44}$ Again, France is characterized by a clear stochastic dominance of the situation with LWS on the initial situation (and of the latter on the situation with WTC); this is less marked for the two other countries. See Bargain (2004a).
} 
Finally, transitions from full- to part-time activity for single women are the consequence of the increase in EMTRs decribed previously; this shift is especially important in France $(6.17 \%$ of selected single women) as it is the country where EMTRs increase the most.

In the UK, the overall net effect on employment was too small to establish the possibility for the WFTC to create work incentives and British studies conclude that the WFTC is fundamentaly justified on distributive grounds. It is difficult to compare our results in a straightfoward way with the situation in the UK since (i) the WFTC came simply as a replacement of the previous family credit, (ii) the WTC simulated here is extended to childless households. Nevertheless, our simulations lead to clear-cut conclusions on the net disincentive effect of this scheme in France and Germany.

Table 5: Response to the WTC Reform

\begin{tabular}{|c|c|c|c|c|c|c|c|c|c|c|}
\hline \multirow[b]{2}{*}{ Country } & \multirow[b]{2}{*}{ Type } & \multicolumn{8}{|c|}{ Simulated responses to WTC (\%) } & \multirow[b]{2}{*}{$\begin{array}{c}\text { in } \% \text { of the } \\
\text { selected } \\
\text { population }\end{array}$} \\
\hline & & $\begin{array}{l}\text { non-work to } \\
\text { work }\end{array}$ & $\begin{array}{c}\text { work to } \\
\text { non-work }\end{array}$ & $\begin{array}{l}\text { part-time to } \\
\text { full-time }\end{array}$ & $\begin{array}{l}\text { full-time to } \\
\text { part-time }\end{array}$ & $\begin{array}{l}\text { net effect on } \\
\text { employment }\end{array}$ & $\begin{array}{c}\text { average } \\
\text { number of hh }\end{array}$ & \multicolumn{2}{|c|}{$90 \%$ confidence intervals } & \\
\hline \multirow[t]{3}{*}{ France } & married women & $0,03 \%$ & $4,35 \%$ & $0,00 \%$ & $0,07 \%$ & $-4,32 \%$ & -168405 & -147794 & -187933 & $-3,14 \%$ \\
\hline & single women & $0,51 \%$ & $0,00 \%$ & $0,01 \%$ & $6,17 \%$ & $0,51 \%$ & 7468 & 4773 & 10109 & $0,14 \%$ \\
\hline & total & & & & & & -160937 & -143021 & -177824 & $-3,00 \%$ \\
\hline \multirow[t]{3}{*}{ Germany } & married women & $0,55 \%$ & $2,79 \%$ & $0,03 \%$ & $0,22 \%$ & $-2,24 \%$ & -89992 & -71646 & -107122 & $-1,36 \%$ \\
\hline & single women & $1,56 \%$ & $0,06 \%$ & $0,27 \%$ & $1,30 \%$ & $1,50 \%$ & 38708 & 25040 & 53361 & $0,59 \%$ \\
\hline & total & & & & & & -51284 & -46606 & -53761 & $-0,78 \%$ \\
\hline \multirow[t]{3}{*}{ Finland } & married women & $0,17 \%$ & $1,34 \%$ & $0,00 \%$ & $0,04 \%$ & $-1,17 \%$ & -3846 & -3267 & -4741 & $-0,77 \%$ \\
\hline & single women & $1,85 \%$ & $0,00 \%$ & $0,00 \%$ & $0,45 \%$ & $1,85 \%$ & 3159 & 2069 & 4562 & $0,63 \%$ \\
\hline & total & & & & & & -687 & -1198 & -179 & $-0,14 \%$ \\
\hline
\end{tabular}

Labor supply responses to the LWS are presented in Table 6. We have stated that the financial gain of working full-time increase twice as much with the WTC than with the LWS in the case of single women. This explains why the positive incentive effects of the LWS on singles' participation is between half and two-third that that was found for the WTC reform (18,000 women versus 39, 000 women with the WTC in Germany, for instance).

The LWS increases financial incentives to work for married women, in particular by reducing the proportion of very small gains. This change combined with larger elasticities in France and to a lesser extent in Germany explains the positive effects on the participation of married women $(3.15 \%$ of selected women living in couple are induced to enter the labor force in France compared to $1.6 \%$ in Germany and only $0.4 \%$ in Finland). 
Overall, the joint positive effect on single and married women leads to the clear conclusion that the LWS could significantly improve social inclusion by enhancing employment in France and, to a lesser extent, in Germany. This result validates the choice made in 2001 by the French government to opt for an individualized policy (see section 2); however, the actual amounts distributed through the Prime pour l'emploi are much smaller than the individual subsidy suggested here and should have hardly any effect on employment (see Bargain, 2004b).

Table 6: Response to the LWS Reform

\begin{tabular}{|c|c|c|c|c|c|c|c|c|c|c|}
\hline \multirow[b]{2}{*}{ Country } & \multirow[b]{2}{*}{ Type } & \multicolumn{8}{|c|}{ Simulated responses to the LWS (\%) } & \multirow[b]{2}{*}{$\begin{array}{l}\text { in } \% \text { of the } \\
\text { selected } \\
\text { population }\end{array}$} \\
\hline & & $\begin{array}{l}\text { non-work to } \\
\text { work }\end{array}$ & $\begin{array}{l}\text { work to } \\
\text { non-work }\end{array}$ & $\begin{array}{l}\text { part-time to } \\
\text { full-time }\end{array}$ & $\begin{array}{l}\text { full-time to } \\
\text { part-time }\end{array}$ & $\begin{array}{l}\text { net effect on } \\
\text { employment }\end{array}$ & $\begin{array}{c}\text { average } \\
\text { number of hh }\end{array}$ & \multicolumn{2}{|c|}{$90 \%$ confidence intervals } & \\
\hline \multirow[t]{3}{*}{ France } & married women & $3,15 \%$ & $0,05 \%$ & $0,52 \%$ & $0,01 \%$ & $3,10 \%$ & 120704 & 106540 & 135977 & $2,25 \%$ \\
\hline & single women & $0,33 \%$ & $0,00 \%$ & $0,64 \%$ & $0,00 \%$ & $0,33 \%$ & 4865 & 3013 & 6787 & $0,09 \%$ \\
\hline & total & & & & & & 125569 & 109553 & 142764 & $2,34 \%$ \\
\hline \multirow[t]{3}{*}{ Germany } & married women & $1,60 \%$ & $0,04 \%$ & $0,27 \%$ & $0,02 \%$ & $1,55 \%$ & 62422 & 50479 & 76516 & $0,95 \%$ \\
\hline & single women & $0,70 \%$ & $0,00 \%$ & $0,13 \%$ & $0,00 \%$ & $0,70 \%$ & 18055 & 11824 & 24643 & $0,27 \%$ \\
\hline & total & & & & & & 80477 & 62303 & 101159 & $1,22 \%$ \\
\hline \multirow[t]{3}{*}{ Finland } & married women & $0,41 \%$ & $0,07 \%$ & $0,02 \%$ & $0,01 \%$ & $0,34 \%$ & 1115 & 862 & 1329 & $0,22 \%$ \\
\hline & single women & $1,17 \%$ & $0,00 \%$ & $0,01 \%$ & $0,00 \%$ & $1,17 \%$ & 2004 & 1406 & 2746 & $0,40 \%$ \\
\hline & total & & & & & & 3119 & 2268 & 4075 & $0,62 \%$ \\
\hline
\end{tabular}

\subsubsection{Cost of the Reforms and Targeting}

Table 7 details the cost and targeting of each reform before and after behavioral responses. First of all, it should be noted that the net cost after labor supply responses is almost identical for both reforms in each country, the result of our calibration exercise using parameter $A$. If we note $\sum C$ total disposable income and $\sum y$ the total gross labor income produced in a country, then the effective net tax levied by the government on households is $T=\sum(y-C)$. The real cost of a reform is then $-\Delta T=\sum(\Delta C-\Delta y)$, that is, larger than the simple variation in disposable income when the reform implies net disincentive effects $(\Delta y<0)$. This is exactly what happens with the WTC. As negative responses are larger in France, Table 7 shows that the real cost increases dramatically for this country once responses are accounted for (from 5.7 up to 7.9 billion EUR). The inverse occurs in the case of an incentive reform so that the real cost of the LWS is smaller than the pre-response cost (7.9 versus 8.3 billion EUR in France for instance). 
By the same token, the net average transfer of WTC increases after responses while the average amount of LWS decreases. In both cases, the number of recipients increases, whether responses are positive (the rise in labor supply may open eligibility) or not (the withdrawal of the woman from the labor market may lead the husband to become eligible). For instance, the number of households eligible to the WTC shifts from 9 to $9.5 \%$ in Germany and the number of households eligible to the LWS shifts from 22.8 to $23.2 \%$ in France. ${ }^{45}$

Table 7: Cost of the Reforms, Including Behavioral Responses

\begin{tabular}{|c|c|c|c|c|}
\hline & & France & Germany & Finland \\
\hline \multicolumn{5}{|l|}{ Working Tax Credit } \\
\hline net cost & billion euros/year & 5,74 & 6,22 & 0,49 \\
\hline real cost including behav. resp. & billion euros/year & 7,90 & 7,17 & 0,52 \\
\hline $\mathrm{nb}$ of recipient (hh) & $\%$ of population & $10,1 \%$ & $9,0 \%$ & $10,6 \%$ \\
\hline $\mathrm{nb}$ after response & idem & $11,2 \%$ & $9,5 \%$ & $10,7 \%$ \\
\hline net average amount per hh & (euros/month) & 207 & 151 & 165 \\
\hline net average amount after response & idem & 256 & 165 & 172 \\
\hline \multicolumn{5}{|l|}{ Low-wage subsidy } \\
\hline net cost & billion euros/year & 8,30 & 7,52 & 0,52 \\
\hline real cost including behav. resp. & billion euros/year & 7,92 & 7,25 & 0,52 \\
\hline $\mathrm{nb}$ of recipient hh & $\%$ of population & $22,8 \%$ & $16,3 \%$ & $21,9 \%$ \\
\hline $\mathrm{nb}$ after response & idem & $23,2 \%$ & $16,5 \%$ & $22,0 \%$ \\
\hline average amount per hh & (euros/month) & 132 & 101 & 84 \\
\hline net average amount after response & idem & 124 & 96 & 83 \\
\hline
\end{tabular}

\subsubsection{Distributive Impacts}

We now tackle the distributive objective, namely the reduction of poverty. We assess the number of households taken out of poverty, holding the pre-reform poverty line constant and considering poverty lines defined as 40,50 and $60 \%$ of the median of equivalized disposable income. ${ }^{46}$

\footnotetext{
${ }^{45}$ Evidently, when labor supply responses are added to the picture, the number of recipients increases by less than the number of 'movers'. Indeed, part of the movers were already entitled to the benefit before the transition. In Germany, this is the case for $23 \%$ (resp. 21\%) of the movers due to the LWS (resp. WTC). These figures are respectively 44 and $32 \%$ in France and 15 and $12.5 \%$ in Finland.

${ }^{46}$ Estimated poverty rates for France are in line with results reported in Mantovani and Sutherland (2001) and derived from 1997 French fiscal data, according to which poverty rates are $2.4 \%, 6.9 \%$ and $12.8 \%$ with a poverty line at $40 \%$, $50 \%$ and $60 \%$ respectively. Finland's poverty rates are however not so close to Mantovani and Sutherland (2001) who this time use figures derived from the 1999 Income Distribution Survey $(2 \%, 4 \%$ and $9 \%$, respectively). The difference in equivalence scale explains only part of the gap. More important is probably the role of the 100\% take-up rate assumed by the microsimulation software, especially with respect to the discrepancies at the very bottom of the distribution. The differences are somewhat larger in Germany where the following poverty rates are obtained from the 1999 GSOEP: 4.5\%, $8.2 \%$ and $13.6 \%$. Is is however well known that take-up of Sozialhilfe is particularly low. The full take-up hypothesis
} 
Let us ignore behavioral responses in a first stage. Table 8 shows that both the WTC and the LWS achieve significant poverty reduction in France as the poverty rate declines from $7.03 \%$ to $6.38 \%$ with the WTC and to $6.48 \%$ with the LWS, at the $50 \%$ poverty line. Surprisingly, the WTC succeeds only slightly better than the wage subsidy and even less when we consider the $40 \%$ line. In Germany, the reduction is not as large and the effects of both reforms are not significantly different. In Finland, the reduction is even smaller than in Germany, except if the $60 \%$ poverty line is considered. Overall in all countries, the reforms redistribute relatively more to the 'richest' among the poor households since poverty reduction is all the smaller as we consider lower poverty lines. ${ }^{47}$ These conclusions derive directly from the specific targetings of the reforms, studied previously and illustrated in Figure 3.

A central question to our study is whether increased labor participation is itself responsible for important moves across the poverty line. Positive labor supply responses of single women (in the case of the WTC) and married women (with the LWS) indeed enhance poverty reduction to some extent. Yet, they do not dramatically change the picture in France or Finland. Things are markedly different in Germany. It turns out that in this country, the number of households taken out of poverty by the WTC is almost doubled (resp. tripled) by behavioral responses when the $50 \%$ (resp. 40\%) poverty line is considered. This result can be explained by the combination of two facts: poor households are most often single individuals and the increase in single women's participation is particularly high when the WTC is introduced in the German system ( see Table 5). ${ }^{48}$

Table 8: Distributive Effects of the Reforms

\begin{tabular}{|c|c|c|c|c|c|}
\hline & baseline & WTC & $\begin{array}{l}\text { WTC + } \\
\text { response }\end{array}$ & LWS & $\begin{array}{l}\text { LWS + } \\
\text { response }\end{array}$ \\
\hline \multicolumn{6}{|l|}{ France } \\
\hline poverty rate - line at $50 \%$ of the median & $7.03 \%$ & $6.38 \%$ & $6.35 \%$ & $6.48 \%$ & $6.45 \%$ \\
\hline variation in the number of poor hh (line at $40 \%$ ) & & $-12.2 \%$ & $-12.4 \%$ & $-8.7 \%$ & $-9.3 \%$ \\
\hline variation in the number of poor hh (line at $50 \%$ ) & & $-9.3 \%$ & $-9.7 \%$ & $-7.9 \%$ & $-8.3 \%$ \\
\hline variation in the number of poor hh (line at $60 \%$ ) & & $-6.6 \%$ & $-6.6 \%$ & $-7.3 \%$ & $-7.3 \%$ \\
\hline \multicolumn{6}{|l|}{ Germany } \\
\hline poverty rate - line at $50 \%$ of the median & $5.65 \%$ & $5.51 \%$ & $5.41 \%$ & $5.52 \%$ & $5.50 \%$ \\
\hline variation in the number of poor hh (line at $40 \%$ ) & & $-4.3 \%$ & $-5.6 \%$ & $-2.8 \%$ & $-3.3 \%$ \\
\hline variation in the number of poor hh (line at $50 \%$ ) & & $-2.5 \%$ & $-4.4 \%$ & $-2.3 \%$ & $-2.8 \%$ \\
\hline variation in the number of poor hh (line at $60 \%$ ) & & $-1.2 \%$ & $-3.7 \%$ & $-0.6 \%$ & $-1.2 \%$ \\
\hline \multicolumn{6}{|l|}{ Finland } \\
\hline poverty rate - line at $50 \%$ of the median & $3.75 \%$ & $3.72 \%$ & $3.71 \%$ & $3.67 \%$ & $3.66 \%$ \\
\hline variation in the number of poor hh (line at $40 \%$ ) & & $-3.2 \%$ & $-3.6 \%$ & $-4.5 \%$ & $-4.9 \%$ \\
\hline variation in the number of poor hh (line at $50 \%$ ) & & $-0.7 \%$ & $-0.9 \%$ & $-2.1 \%$ & $-2.4 \%$ \\
\hline variation in the number of poor hh (line at $60 \%$ ) & & - & - & $-2.5 \%$ & $-2.5 \%$ \\
\hline
\end{tabular}

notwithstanding, the pattern of poverty rates quite closely matches statistics derived from non simulated data. Moreover, the few discrepancies encountered are not so relevant to the present analysis, given that we are more interested in the relative movements in and out of poverty under both reforms, than in the absolute level of headcount ratios.

${ }^{47}$ The $40 \%$ line captures the poorest households which are composed to a higher proportion of inactive households, that is, households that do not benefit from the reforms.

${ }^{48}$ The proportion of single adult amongst the poor population is around $70 \%$ in France and Germany when the $50 \%$ poverty line is considered (and respectively $75 \%$ and $67 \%$ with the $40 \%$ line). 


\subsubsection{Cost Efficiency}

Finally, we study the cost efficiency of the reforms to achieve either incentive or distributive objectives. For this purpose, we simply compute the cost per woman taking up work (when the net employment effect is positive) and the cost per household taken out of poverty. Results are presented in Table 9.

In relative terms, the real (post-response) cost of both reforms corresponds to $0.54 \%$ of GDP in France, $0.33 \%$ in Germany and $0.40 \%$ in Finland. In Finland, the labor supply responses and distributive effects of both reforms are much smaller than in France and Germany, which leads to extremely high efficiency costs, whether social inclusion or poverty reduction are considered.

Efficiency costs are very high in the two other countries as well and markedly higher in Germany. It would cost 63,000 EUR in France and 90,000 EUR in Germany to bring a woman back to work through the LWS reform and respectively 53,000 and 131,000 EUR to take a woman out of poverty by means of the WTC. ${ }^{49}$ If poverty reduction is the central policy objective, then the WTC is preferable. However, the cost per household out of poverty is only slightly larger with the LWS which also provides net positive effects on employment.

This figures may seem large but are not so far from previous experiences. According to Pearson (2002), the cost per net job created has ranged between 30,000 and 100,000\$ throughout in the various MWP policies experienced in the UK and the US. Our results for the LWS are in this range. Both reforms suggested here are relatively expensive (as is the WFTC in the UK) but the cost is not the only criterion by which these policies must be judged. Still, the question of funding these reforms - highly problematic in the present European budgetary context - remains. Recent trends then seem to abandon somehow the idea of expensive in-work transfers. The orientations of the Harz IV reform in Germany tend to privilege workfare concepts. In France too, the proposal of Revenu Minimum d'Activité would render social benefits conditional on work.

\section{Concluding Remarks}

In this paper, we present an extended analysis of 'making work pay' policies in Finland, France and Germany, three countries which suffer from particularly large potential inactivity traps due to meanstested generous social assistance. More specifically, we introduce two types of employment-conditional payments in the three countries under consideration. The first instrument is a working tax credit in the fashion of the British WFTC and the second is a simple wage subsidy. These two reforms illustrate the typical opposition between family-based instruments and individual transfers, which characterizes recent trends in 'making work pay' policies in OECD countries. In particular, the former type of instrument is conditioned on household income and is known to yield disincentive effects for women whose partner is employed.

This study is one of the very first cross-country analyses of tax-benefit reforms conducted in a truly comparative and comprehensive way. Firstly, female labor supply estimations are carried out using datasets that are rendered homogeneous across countries. Secondly, tax analysis is performed using the integrated microsimulation of European tax-benefit systems EUROMOD. Thirdly, the microsimulation is combined to structural discrete-choice models in order to predict potential behavioral responses to the

\footnotetext{
${ }^{49}$ Note that the cost to bring a single woman back to work using the WTC reform would be 180,000 EUR in Germany and considerably higher in France. This aspect is not represented in the table.
} 
Table 9: Cost Effiency in Achieving Social Inclusion or Poverty Reduction

\begin{tabular}{|c|c|c|c|}
\hline \multirow[b]{2}{*}{ Working Tax Credit } & France & Germany & Finland \\
\hline & & & \\
\hline $\begin{array}{l}\mathrm{Nb} \text { of households out of poverty due to the reform } \\
\qquad \text { in } \% \text { of total population }\end{array}$ & $\begin{array}{c}150,121 \\
0.65 \%\end{array}$ & $\begin{array}{c}54,654 \\
0.14 \%\end{array}$ & $\begin{array}{c}583 \\
0.02 \%\end{array}$ \\
\hline $\begin{array}{l}\mathrm{Nb} \text { of households out of poverty due to behav. resp. } \\
\text { in \% of total population }\end{array}$ & $\begin{array}{l}5,984 \\
0.03 \%\end{array}$ & $\begin{array}{c}39,748 \\
0.10 \%\end{array}$ & $\begin{array}{c}242 \\
0.01 \%\end{array}$ \\
\hline $\mathrm{Nb}$ of households back to work & $\begin{array}{c}-160,937 \\
-0.70 \%\end{array}$ & $\begin{array}{c}-51,284 \\
-0.13 \%\end{array}$ & $\begin{array}{l}-687 \\
-0.03 \%\end{array}$ \\
\hline Cost per household out of poverty (EUR) & 52,638 & 131,230 & 888,575 \\
\hline Low-wage subsidy & & & \\
\hline $\begin{array}{l}\mathrm{Nb} \text { of households out of poverty due to the reform } \\
\text { in \% of total population }\end{array}$ & $\begin{array}{c}127,528 \\
0.55 \%\end{array}$ & $\begin{array}{c}49,685 \\
0.13 \%\end{array}$ & $\begin{array}{l}1,882 \\
0.08 \%\end{array}$ \\
\hline $\begin{array}{l}\mathrm{Nb} \text { of households out of poverty due to behav. resp. } \\
\text { in \% of total population }\end{array}$ & $\begin{array}{l}6,980 \\
0.03 \%\end{array}$ & $\begin{array}{l}9,937 \\
0.03 \%\end{array}$ & $\begin{array}{l}235 \\
0.01 \%\end{array}$ \\
\hline $\mathrm{Nb}$ of households back to work & $\begin{array}{c}125,569 \\
0.55 \%\end{array}$ & $\begin{array}{c}80,477 \\
0.21 \%\end{array}$ & $\begin{array}{l}3,119 \\
0.13 \%\end{array}$ \\
\hline Cost per household out of poverty (EUR) & 62,143 & 145,902 & 276,239 \\
\hline Cost per household back to work (EUR) & 63,112 & 90,077 & 166,690 \\
\hline
\end{tabular}

reforms. Estimations make use of a similar specification across country to compare the determinants of labor supply. Finally, differences in 'framework conditions' across countries are emphasized throughout the analysis, notably the differences in income and wage rate distributions and the way tax-benefit reforms interact with national systems in force. These issues turn out to be crucial to explain the differences in the effects of each reform across countries. They are important issues to be dealt with when designing tax-benefit reforms aimed at reshaping work incentives at national level.

We find that the overall female employment decreases after the introduction of the working tax credit. The participation of married women decline in all three countries and especially in France, where labor supply is slightly more elastic and where the net gain to work decreases substantially for second-earners (assumed to be the wives). This effect is only partially offset by a positive impact of the reform on single women's labor supply in Finland and in Germany. The individual wage subsidy is calibrated in order to reach the same budgetary cost after behavioral responses. In that case, we find that married women are encouraged to take up a job, especially in France and Germany.

In these two countries, an individual transfer seems then to contribute positively to the objective of social inclusion, understood as the maximization of transitions into work. In Finland however, the effects are extremely low, which is mainly due to small labor supply elasticities in a country where female participation is already high. Policy intervention aimed at enhancing employment should attempt to levy on the demand-side by reducing the cost of low-productive work for employers. However, such a policy should be recommended only if demand-side elasticities are large enough; Böckerman and Jäntti (2004) confirm the importance of demand-side aspects. As a matter of fact, the Finnish authorities are currently considering possible reductions in employer social security contributions for low-wage jobs.

Results convey the idea that our definition of the social inclusion objective should be changed slightly. In effect, it is noticeable that a large proportion of poor households (between two-third and three-quarter in France and Germany) are single individuals. Interestingly enough, a substantial number of poor 
single women would be induced to work by the working tax credit in Germany. As a result, this reform cannot be rejected if inclusion means encouraging employment of the poorest, even at the price of creating disincentive effects for second-earners in couples. This new definition also implies positive externalities, not accounted for here, as described by Phelps (2000). ${ }^{50}$ Such objective justifies the need for measures which are better targeted to sub-groups of the population and in particular, more generous in-work transfers to lone mothers.

Both the family-based tax credit and the individual wage subsidy achieve significant poverty reduction in France and, to a lesser extent, in Germany. Surprisingly, the tax credit performs only slightly better than the wage subsidy as both reforms target mainly 'the richest among the poors'. To echo the previous argument relative to social inclusion of the poorest households, notice that in Germany, the increased participation of poor single women induced by the working tax credit contributes substantially to poverty reduction. Once accounting for this effect, the tax credit performs much better than the individual transfer on that account. Naturally, the tax credit contributes more broadly to redistribution than can be seen through the poverty criterion. In particular, it achieves an important transfer to the first-half of the income distribution, with the exception of the very first decile, while the individual wage subsidy is more spread.

Ultimately, the ranking of policy objectives depends on social preferences which are unfortunately unknown. Following Spadaro (2004), we could draw conclusions for a broad range of values for the social aversion towards inequality and find out the range over which one reform is socially preferred to the other. This type of analysis implies additional assumptions and in particular interpersonal utility comparisons, which requires further work left for future research. More pragmatically, we have focused on policy criteria often retained by decision-makers and which ground the debates on the reform of European welfare systems. These criteria may not be easily incorporated into a social welfare function of the usual kind.

\section{References}

[1] Aaberge, R., U. Colombino and S. Strøm (2000): "Labor Supply Responses And Welfare Effects From Replacing Current Tax Rules By A Flat Tax: Empirical Evidence From Italy, Norway And Sweden", Journal of Population Economics, 13, 4, 595-621.

[2] Atkinson A.B, Bourguignon F., Chiappori P.A., (1988): "What Do We Learn About Tax Reforms from International Comparisons? France and Britain", European Economic Review, 32.

[3] Bargain, O. (2004a): "Household labor supply and taxation: household versus individual perspectives", PhD dissertation, DELTA and EHESS.

[4] Bargain, O. (2004b): "Aides au retour à l'emploi et activité des femmes en couple", Revue de l'OFCE, $88,59-88$.

[5] Bargain, O. and I. Terraz (2003): "Evaluation et mise en perspective des effets incitatifs et redistributifs de la Prime pour l'Emploi.", forthcoming in Economie et Prévision.

\footnotetext{
${ }^{50}$ Phelps argues that there are potentially important social and economic externalities associated with entering the labor market (he insists on the fact to hold a full-time job): "Bringing marginalized groups, including those who work in the underground economy, into mainstream economic activities may generate beneficial outcomes for society as a whole, for example through the amelioration of problems like crime, social destitution, drug etc."
} 
[6] Bargain, O. and K. Orsini (2004): "Designing in-work policies in Europe: a three-country exercise", mimeo.

[7] Bertola, G. (2000): "Policy choices and interactions with existing instruments", OECD Economic Studies, 31, 185-196.

[8] Blundell, R.W. and F. Laisney (1988): "A labour supply model for married women in France: taxation, hours constraints and job seekers", Annales d'Economie et de Statistiques, 11, 41-71.

[9] Blundell, R.W. and T. MaCurdy (2000): "Labor Supply: A Review of Alternative Approaches", in Ashenfelter and Card (eds), Handbook of Labor Economics, Elsevier North-Holland.

[10] Blundell, R.W., A. Duncan, J. McCrae and C. Meghir (2000): "The Labour Market Impact of the Working Families' Tax Credit", Fiscal Studies, 21, 1, 75-103.

[11] Blundell, R., V. Lechene et M. Myck (2002): "Does the representation of family decision processes matter? Collective decisions and fiscal reforms in the UK", mimeo, IFS, London.

[12] Böckerman, P. and M. Jäntti (2004): "Is variation in hours of work driven by supply or demand? Evidence from Finnish manufacturing industries", Labor Institute for Economic Research discussion paper, 196, Helsinki.

[13] Boeters, S., N. Gürtzgen and R. Schnabel (2003): "Reforming social welfare in Germany - an applied general equilibrium analysis", ZEW working paper.

[14] Bonin, H., W.Kempe and H.Schneider (2002): "Household labor supply effects of low-wage subsidies in Germany", IZA Discussion Paper, 637.

[15] Bourguignon, F. and T. Magnac (1990): "Labour supply and taxation in France", Journal of Human Resources, 25, 358-389.

[16] Bourguignon F, O’Donoghue C., Sastre J., Spadaro A., Utili F.(1997): "Eur3: A Prototype European Tax-Benefits Model", DAE Working Paper, 9723, Microsimulation Unit, Cambridge University.

[17] Buchel F., A. Mertens and K. Orsini (2003): "Is Mothers' Employment an Effective Means to Fight Family Poverty? Evidence From Seven European Countries", Luxembourg Income Study Working Paper Series, 363.

[18] Callan, T,. S. Dex, N. Smith and J.D. Vlasblom (1999): "Taxation of Spouses: a Cross-Country Study of the Effects on Married Women's Labour Supply", Centre for Labour Market and Social Research (Denmark), working paper 99-02.

[19] Callan, T. and A. Van Soest (1996): "Family labor supply and taxes in Ireland", mimeo Tilburg University.

[20] Choné, P., D. Le Blanc and I. Robert-Bobée (2003): "Female labor supply and child care in France", CREST working paper.

[21] De Lathouwer L.(1996): "A Case Study of Unemployment Scheme for Belgium and The Netherlands", in Microsimulation and Public Policy, Harding editor, North Holland, Amsterdam. 
[22] Dilnot, A. and J. McCrae (1999/2000): "The family credit system and the working families tax credit in the United Kingdom", IFS briefing note, 3, and OECD Economic Studies, 31.

[23] Duncan, A. and C. Giles (1996): "Labor supply incentives and recent family credit reforms", Economic Journal, 106, 142-56.

[24] Duncan, A. and C. Giles (1998): "The labor market impact of the working family tax credit", International Institute for Public Finance, Cordoba Conference.

[25] Duncan, A. (2003): “Making work pay' policies and employment incentives", CESifo Summer Institute, Venice.

[26] Eissa, N. and H. Hoynes (1998): "The Earned Income Tax Credit and the labor supply of married couples", NBER working paper, 6856.

[27] Euwals, R. and A. Van Soest (1999): "Desired and actual labor supply of unmarried men and women in the Netherlands", Labor Economics, 6, 95-118.

[28] Gradus, R. and J. Julsing (2000): "Comparing different european income tax policies making work pay", memo OCFED.

[29] Gregg, P., P. Johnson and H. Reed (1999), Entering work and the British tax and benefit system, IFS Monograph, London.

[30] Gurgand, M. and D. Margolis (2001): "RMI et revenus du travail . une évaluation des gains financiers à l'emploi", Economie et Statistique, 6-7.

[31] Haan, P. (2004): "Discrete choice labor supply: conditional logit vs. random coefficient models", DIW discussion paper, 394, Berlin.

[32] Haan, P. and Steiner V. (2004): "Distributional and fiscal effects of the German tax reform 2000 a behavioral microsimulation analysis", DIW discussion paper, 419, Berlin.

[33] Heckman, J. (1979): "Sample selection bias as a specification error", Econometrica, 47, 151-161.

[34] Heckman, J. (1993): "What has been learned bout labor supply in the past twenty years?", American Economic Review, 83, 2, 116-121.

[35] Hoynes, H. (1996): "Welfare Transfers in Two-Parent Families: Labor Supply and Welfare Participation Under AFDC-UP", Econometrica, 64, 295-332.

[36] Ilmakunnas, S. and S. Pudney (1990): "A model of female labor supply in the presence of hours restrictions", Journal of Public Economics, 41, 183-210.

[37] Immervoll, H. and C. O'Donoghue (2001): "Welfare benefits and work incentives: an analysis of the distribution of net replacement rates in Europe using EUROMOD, a multi-country microsimulation model", EUROMOD working paper EM4/01.

[38] Immervoll, H., H. J. Kleven, C. T. Kreiner and E. Saez (2003): "Welfare reform in European countries: a microsimulation analysis", EUROMOD working paper.

[39] Kuismanen, M. (2000): "Labor supply and income tax changes: a simulation study for Finland", Bank of Finland discussion papers, 5/2000. 
[40] Laine, V. (2002): "Evaluating tax and benefit reforms in 1996-2001", VATT discussion paper, 280.

[41] Laroque, G. and B. Salanié (2000): "Une décomposition du non-emploi en France", Economie et Statistique, 328, 3-20.

[42] Laroque, G. and B. Salanié (2002), Institutions et emploi, le marché du travail des femmes en France, Economica.

[43] MaCurdy, T. (1992): "Work Disincentives Effects of Taxes: A Reexamination of some evidence", American Economic Review, Papers and Proceedings, 82, 243-249.

[44] Mantovani, D. and Sutherland H. (2001): "Social Indicators and other Income Statistics using the Euromod Baseline: a Comparison with Eurostat and National Statistics", EUROMOD working paper EM1/03.

[45] Martin, J. and D.Grubb (2001): "What works and for whom: a review of OECD countries' experience of active labour market policies", OECD, Paris.

[46] McFadden, D. (1973): "Conditional logit analysis of qualitative choice behavior", in P. Zarembka, ed., Frontiers in Econometrics, Academic Press, NY.

[47] McFadden, D. and K. Train (2000): "Mixed MNL Models for Discrete Response", Journal of Applied Econometrics, 15, 447-470.

[48] Meyer, B.D. and Rosenbaum (2001): "Welfare, the Earned Income Tax Credit and the labor supply of single mothers", Quaterly Journal of Economics, 116, 1063-1114.

[49] Moffitt, R. (1984): "Estimation of a joint wage-hours labor supply model", Journal of Labor Economics, 2, 550-556.

[50] Orsini, K. (2004): "The 2001 Belgian tax reform: equity and efficiency", EUROMOD working paper.

[51] Pearson, M. (2002): 'International experience of 'making work pay' policies', Working Paper OECD.

[52] Pearson, M. and S. Scarpetta (2000): "An overview: what do you know about policies to make work pay?", OECD Economic Studies, 31, 11-24

[53] Pencavel, J.H. (1986): "Labor supply of men: a survey", in O. Ashenfelter and R. Layard (eds), Handbook of Labor Economics, vol.1, Amsterdam, North-Holland.

[54] Phelps, E. (2000): "The importance of inclusion and the power of job subsidies to increase it", OECD Economic Studies, 31, 85-114.

[55] Saez, E. (2002): "Optimal income transfer programs: intensive versus extensive labor supply responses", Quaterly Journal of Economics, 117(3), 1039-1073.

[56] Service Publique Fédérale Finances (2003), Service d'Etudes et de Documentation, Memento Fiscal, 15 .

[57] Spadaro, A. (2004): "Microsimulation and normative policy evaluation: an application to some EU tax-benefit systems", Journal of Public Economic Theory, for thcoming. 
[58] Steiner, V. and K. Whrolich (2003): "Household taxation, income splitting and labor supply incentives - a microsimulation study for Germany", CESifo Venice Summer Institute 2003.

[59] Sutherland, H. (2001): "Final report EUROMOD: an integrated European tax-benefit model", EUROMOD working paper EM9/01.

[60] Tummers, M. and I.Woittiez (1991): "A simultaneous wage and labor supply model with hours restriction", Journal of Human Resources, 26, 393-423.

[61] Van Soest, A. (1995): "Structural Models of Family Labor Supply: a Discrete Choice Approach", Journal of human Resources, 30, 63-88.

\section{Appendices}

\section{Data and Sample Selection}

Finnish data are provided by the Income Distribution Survey, which contains a combination of register data and information gathered through interviews by Statistics Finland. The dataset refers to 1998 and contains detailed socio-economic information for 25,010 individuals living in 9,345 households. German data come from the German Socio-Economic Panel (GSOEP) initiated by the German Institute for Economic Research (DIW) in 1984. Unlike Finland, the data are collected yearly through interviews only. The 1998 dataset contains information on 18,772 individuals living in 7,677 households. The data used for France are taken from the French Household Budget Survey 1994 collected by INSEE; monetary variables have been grossed up to 1998, assuming demography constant. No structural change has occured in the tax-benefit system between 1994 and 1998 so that there is no inconsistency between the simulated system (1998) and observed behaviors (see Bargain and Terraz, 2003). The sample contains information on 28, 973 individuals living in 11, 220 households. All three datasets have been reweighted to be representative of the whole population and rendered homogeneous in the framework of the EUROMOD project, including similar variables definitions (see Sutherland, 2001).

For each country, we select a sample of married and cohabiting couples and a sample of single women. In each case, we keep only households where adults are aged between 25 and 64 and available for the labor market. For this purpose, households where adults are disabled, student or retired are excluded. So are households of self-employed or farmers (and civil servants, for France). The labor supply behavior of these two categories (and civil servants in the case of France, whose job is guaranteed for life) may indeed be rather different from salary workers and would require a different modeling strategy alltogether. Moreover, independent workers are subject to income tax rules which are substantially different from the ones applied to salary income and which require additional information not available here. Households where adults are unemployed are taken out of the selection. This corresponds to a pure supply-side strategy in which we focus on non-rationed workers. ${ }^{51}$

Employees not reporting important pieces of information (e.g worked hours) are excluded from each sample. To further increase data homogeneity, extreme households are selected out, notably the ones receiving important levels of non-labor income, the ones with more than 3 children or whose children earn substantial earnings (more than half the cumulated earnings of the parents). Households with more than

\footnotetext{
${ }^{51}$ Withdrawing unemployed individuals enables to discard job seekers but also leads to exclude discouraged workers. Reliable information to identify job seekers would be necessary for a more comprehensive approach.
} 
two decision-makers in the case of couples (i.e other adults than the basic couple) are also withdrawn from the sample.

Descriptive statistics of the selected samples are presented in Tables 10 and 11 for couples and singles respectively. Wage rates are not provided directly and must be computed as earnings divided by the number of work hours. Wage rates for non-working women are predicted using the usual Heckman (1979) two-stage estimation technique. ${ }^{52}$

Table 10: Descriptive Statistics for Couples

\begin{tabular}{|c|c|c|c|c|c|c|}
\hline & \multicolumn{2}{|c|}{ France } & \multicolumn{2}{|c|}{ Germany } & \multicolumn{2}{|c|}{ Finland } \\
\hline & Women & Men & Women & Men & Women & Men \\
\hline Participation* & $70,5 \%$ & $99,1 \%$ & $63,2 \%$ & $95,7 \%$ & $73,6 \%$ & $90,1 \%$ \\
\hline Working time (hours/week) / participants & 35,7 & 42,0 & 33,3 & 38,2 & 37,0 & 40,0 \\
\hline Working time (hours/week) / all & 26,0 & 41,9 & 21,6 & 36,7 & 35,5 & 39,8 \\
\hline Gross wage rate (euros/hour) / participants & 10,5 & 12,8 & 12,2 & 15,8 & 11,8 & 15,5 \\
\hline Gross wage rate (euros/hour) / all** & 9,9 & 12,8 & 11,8 & 15,8 & 11,4 & 15,3 \\
\hline Average age & 38,2 & 40,4 & 38,4 & 40,9 & 40,2 & 41,8 \\
\hline Primary education & $30,7 \%$ & $17,9 \%$ & $14,6 \%$ & $11,1 \%$ & $16,1 \%$ & $18,6 \%$ \\
\hline Vocational training & $37,9 \%$ & $46,0 \%$ & $48,7 \%$ & $44,8 \%$ & $35,2 \%$ & $37,8 \%$ \\
\hline High school diploma & $14,8 \%$ & $17,9 \%$ & $23,2 \%$ & $25,9 \%$ & $27,5 \%$ & $18,1 \%$ \\
\hline University studies & $16,7 \%$ & $18,2 \%$ & $8,5 \%$ & $14,9 \%$ & $21,2 \%$ & $25,4 \%$ \\
\hline Average number of children & \multicolumn{2}{|c|}{1,47} & \multicolumn{2}{|c|}{1,11} & \multicolumn{2}{|c|}{1,19} \\
\hline Presence of child 0-2 & \multicolumn{2}{|c|}{$17,1 \%$} & \multicolumn{2}{|c|}{$11,9 \%$} & \multicolumn{2}{|c|}{$15,9 \%$} \\
\hline Presence of child 3-5 & \multicolumn{2}{|c|}{$20,2 \%$} & \multicolumn{2}{|c|}{$15,7 \%$} & \multicolumn{2}{|c|}{$18,6 \%$} \\
\hline Presence of child 6-11 & \multicolumn{2}{|c|}{$33,8 \%$} & \multicolumn{2}{|c|}{$29,4 \%$} & \multicolumn{2}{|c|}{$29,4 \%$} \\
\hline $\mathrm{Nb}$ of selected households & \multicolumn{2}{|c|}{2095} & \multicolumn{2}{|c|}{1265} & \multicolumn{2}{|c|}{1632} \\
\hline Corresponding population & \multicolumn{2}{|c|}{3898106} & \multicolumn{2}{|c|}{4020163} & \multicolumn{2}{|c|}{329343} \\
\hline$\%$ of total population & \multicolumn{2}{|c|}{$16,9 \%$} & \multicolumn{2}{|c|}{$10,5 \%$} & \multicolumn{2}{|c|}{$14,0 \%$} \\
\hline
\end{tabular}

The distribution of working hours for female worker of the selected samples is represented in Figure 4. A usual feature in continental Europe, mostly driven by demand-side and institutional constraint, is that the pattern of hours appears fairly rigid as it presents concentration around a limited number of hours choices in all three countries. In that case, the discrete approach retained here seems particularly well suited (see Van Soest, 1995). The distribution of male hours - available upon request - is much more concentrated, quasi-exclusively around full time. In addition, male participation is very high. Overall, these empirical evidences justify the choice of a modeling strat egy focusing purely on female labor supply.

\footnotetext{
${ }^{52}$ Because the labor supply models are nonlinear, it is necessary to take the wage rate prediction errors explicitely into account for a consistent estimation of the models, for instance by integrating the disturbance term of the wage equation in the likelihood. Practically, this is done by approximating the integral by a simulated mean. However, for a tractable number of draws (20), this correction did not significantly change our results.
} 
Table 11: Descriptive Statistics for Single Women

\begin{tabular}{lccc}
\hline & France & Germany & Finland \\
\cline { 2 - 4 } Participation* & $96,8 \%$ & $79,3 \%$ & $80,1 \%$ \\
Working time (hours/week) / participants & 37,4 & 36,0 & 37,7 \\
Working time (hours/week) / all & 36,6 & 28,7 & 36,7 \\
Gross wage rate (euros/hour) / participants & 11,2 & 12,4 & 12,5 \\
Gross wage rate (euros/hour) / all** & 11,1 & 12,8 & 11,8 \\
Average age & 40,6 & 38,5 & 42,5 \\
Primary education & $22,3 \%$ & $21,0 \%$ & $17,6 \%$ \\
Vocational training & $32,7 \%$ & $44,6 \%$ & $36,1 \%$ \\
High school diploma & $15,1 \%$ & $22,5 \%$ & $26,2 \%$ \\
University studies & $30,0 \%$ & $11,9 \%$ & $20,2 \%$ \\
Average number of children & 0,64 & 0,59 & 0,54 \\
Presence of child 0-2 & $2,3 \%$ & $4,9 \%$ & $1,9 \%$ \\
Presence of child 3-5 & $4,8 \%$ & $6,2 \%$ & $5,3 \%$ \\
Presence of child 6-11 & $14,5 \%$ & $19,2 \%$ & $12,0 \%$ \\
Nb of selected households & 664 & 453 & 416 \\
Corresponding population & 1458 464 & 2579207 & 171100 \\
\% of total population & $6,3 \%$ & $6,8 \%$ & $7,3 \%$ \\
\hline "non-participation according to our discretization (i.e working less than 15 hours per week or than 6 months per year) \\
** these include predicted wages & & & \\
& & &
\end{tabular}

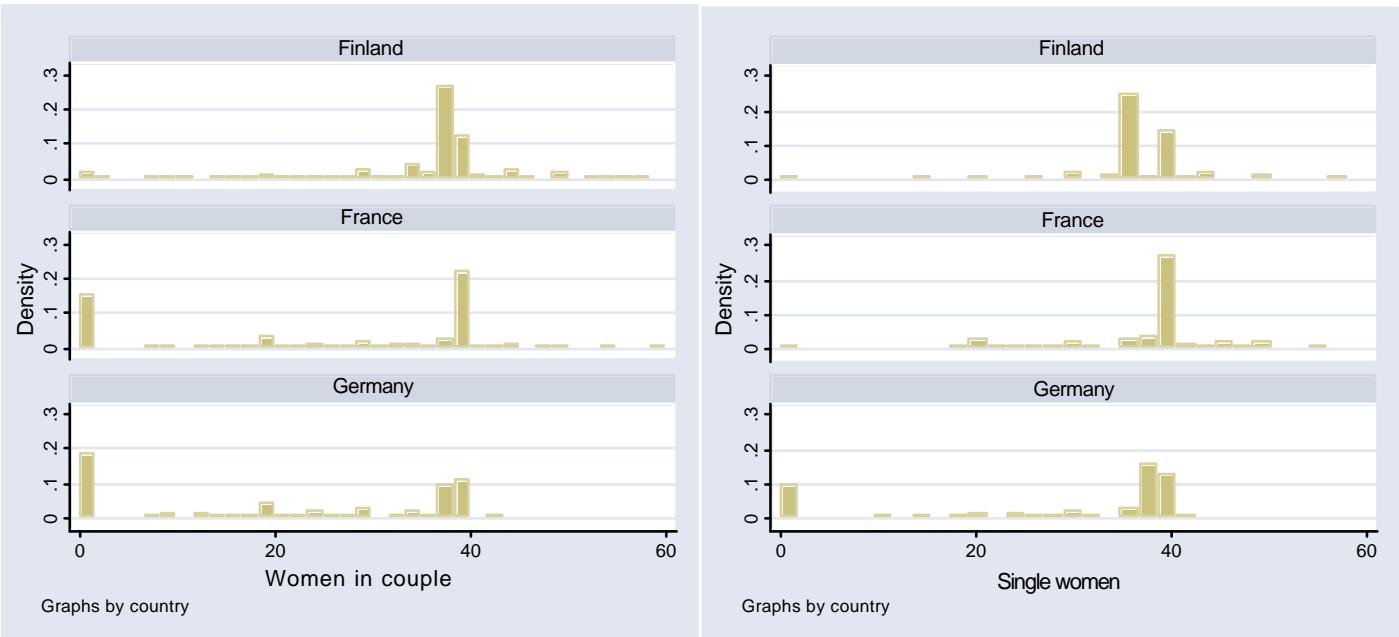

Figure 4: Distribution of Working Time (hours/week) 


\section{Structural Model of Labor Supply and Tax-benefit Simulation}

Discrete-choice models make use of an explicit parameterization of consumption-leisure preferences and the problem is reduced to utility-maximization among a discrete set of possibilities, which allows to avoid the computational and analytical difficulties encountered in the continuous setting of Hausman $(1981,1985)$. The main advantage derives from the possibility to account for nonlinearities and nonconvexities in the budget sets. It also simultaneously explains the participation decision and the choice of working hours. For these reasons, discrete models have been used extensively for ex-ante evaluation of current or topical tax-benefit reforms. ${ }^{53}$

We rely here on the multinomial/conditional logit model. If household $i$ is offered to choose one among $J$ work durations for the female adult, it is assumed that the utility the household may derive from alternative $j(=1, \ldots, J)$ is given by:

$$
V_{i j}=U\left(H_{j}, C_{i j}, Z_{i}\right)+\epsilon_{i j},
$$

where $U$ is a conventional utility function which depends on female work duration $\left(H_{j}\right)$ and consumption $\left(C_{i j}\right)$ as well as on a vector $Z_{i}$ of household characteristics. Women are assumed to choose between nonparticipation $\left(H_{1}=0\right)$, part-time $\left(H_{2}=20\right.$ hours/week) and full-time $\left(H_{3}=39\right.$ hours per week). The actual utility derived from alternative $j$ for household $i, V_{i j}$, also includes an error term $\epsilon_{i j}$ that is assumed to be identically and independently distributed across alternatives and households according to a type I-extreme value distribution. ${ }^{54}$ Under this distributional assumption, McFadden (1973) proves that the probability that alternative $k$ is chosen by household $i$ is given by:

$$
P_{i k}=\operatorname{Pr}\left(V_{i k} \geq V_{i j}, \forall j=1, \ldots, J\right)=\frac{\exp U\left(H_{k}, C_{i k}, Z_{i}\right)}{\sum_{j=1}^{J} \exp U\left(H_{j}, C_{i j}, Z_{i}\right)} .
$$

The likelihood of a sample of observed choices can be derived from that expression as a function of the preference parameters of $U$ whose estimates are obtained by maximum likelihood techniques. We choose a quadratic specifiction of the utility as in Blundell et al. (2000). Linear terms vary with household sociodemographic characteristics (vector $Z_{i}$ above) supposed to pick up variation in tastes for female work across households. Among usual regularity conditions, $C$-monotonicity and quasi-concavity seem natural minimum requirements and are imposed as constraints in the likelihood maximization (see Bargain, 2004a).

In the present static framework, consumption is equivalent to disposable income:

$$
C_{i j}=D\left(w_{i} H_{j}, y_{i}, Z_{i}\right)
$$

Disposable income is expressed as a function $D$, the arguments of which are some socio-demographic characteristics of the household as well as gross incomes. In our setting, endogenous income $w_{i} H_{j}$ in alternative $j$ corresponds to labor income of a single or of a wife (in couples), with $w_{i}$ the wage rate of

\footnotetext{
${ }^{53}$ See Van Soest (1995) for the Netherlands, Hoynes (1996) for the US and Blundell et al. (2000) for the UK, among others.

${ }^{54}$ The assumption of independence across alternatives results in the property of independence of irrelevant alternatives (IIA). This shortcoming can be avoided by introducing random terms accounting for unobserved heterogeneity across households (see McFadden and Train, 2000). With the random parameter model, however, the computation of bootstrapped confidence intervals becomes computationally non-tractable, as proved by Haan (2004). In addition, the latter shows that the results in terms of wage elasticities from a conditional logit do not differ significantly from the results of a random parameter logit. We obtain the same results for the three models presented here and decide to rely on the conditional logit specification so as to derive confidence intervals of our estimates.
} 
the person considered. Exogenous income $y_{i}$ includes non-labor income, such as capital income, and the earnings of the husband (in couples). As a result, $D$ represents the way the tax-benefit system transforms gross income into disposable income. In general, this function relies on a fairly complex set of tax-benefit rules computed by microsimulation.

In the present paper, disposable income at each discrete hours choice is computed using EUROMOD microsimulation. EUROMOD is a tax and benefit calculator based on homogeneous micro-data on income, earnings, labor force participation as well as socio-demographic variables gathered for the member countries of the European Union. For each country and for the year 1998, this microsimulation model enables us to compute all social contributions, direct taxes and transfers to individuals and households and thus to calculate household disposable income, replacement rates and effective marginal tax rates. An introduction to the model and a descriptive analysis of European systems are provided by Immervoll and O'Donoghue (2001) and Sutherland (2001).

\subsection{Results of Estimations}

As we use the same labor supply methodology and homogenous datasets with the same definitions of variables, it is possible to provide a reliable picture of the differences and similarities in labor supply behaviors in France, Germany and Finland. Callan, Dex, Smith and Vlasblom (1999) provide similar cross-country comparisons for Britain, Denmark, Ireland and Germany.

Table 12 presents the results of the estimations for women in couples. Among estimated taste parameters for income, only the regional dummy and female age are significant in all three countries. On the contrary, estimates for hours are more often significant. As could have been expected, the marginal utility of work decreases with the presence of children, and especially very young children. Women prefer to work significantly more if located in East Germany (positive coefficient of the regional dummy), which is a usual result. Marginal utility of work decreases with age in France, suggesting a move towards single-earner couples as the household ages (or a cohort effect). In Finland, it turns out that women significantly prefer to work more when married, all things being equal (including the presence of children). This explains why we find larger elasticities for married women than for single women, a rather unusual result.

Table 13 presents the results of the estimations for single women. Among estimated taste parameters for income, only female age is significant in all countries. On the contrary, estimates for hours are more often significant in France and Germany. The marginal utility of work decreases with the presence of children between 0 and 2 in all three countries; the coefficients for older children are not always significant however, except in Germany where the disutility of work decreases with the age of the children (which may also reflect decreasing childcare costs as the children get older and go to school). Again, women prefer to work significantly more when living in East Germany and less when they grow older (in France and Germany).

Note that quasiconcavity in $H$ is not respected as coefficients of $H^{2}$ are always positive. This could be due to the fact that hours variables not only represent distaste for work but also account for variable 
Table 12: Estimation Results for Women in Couple

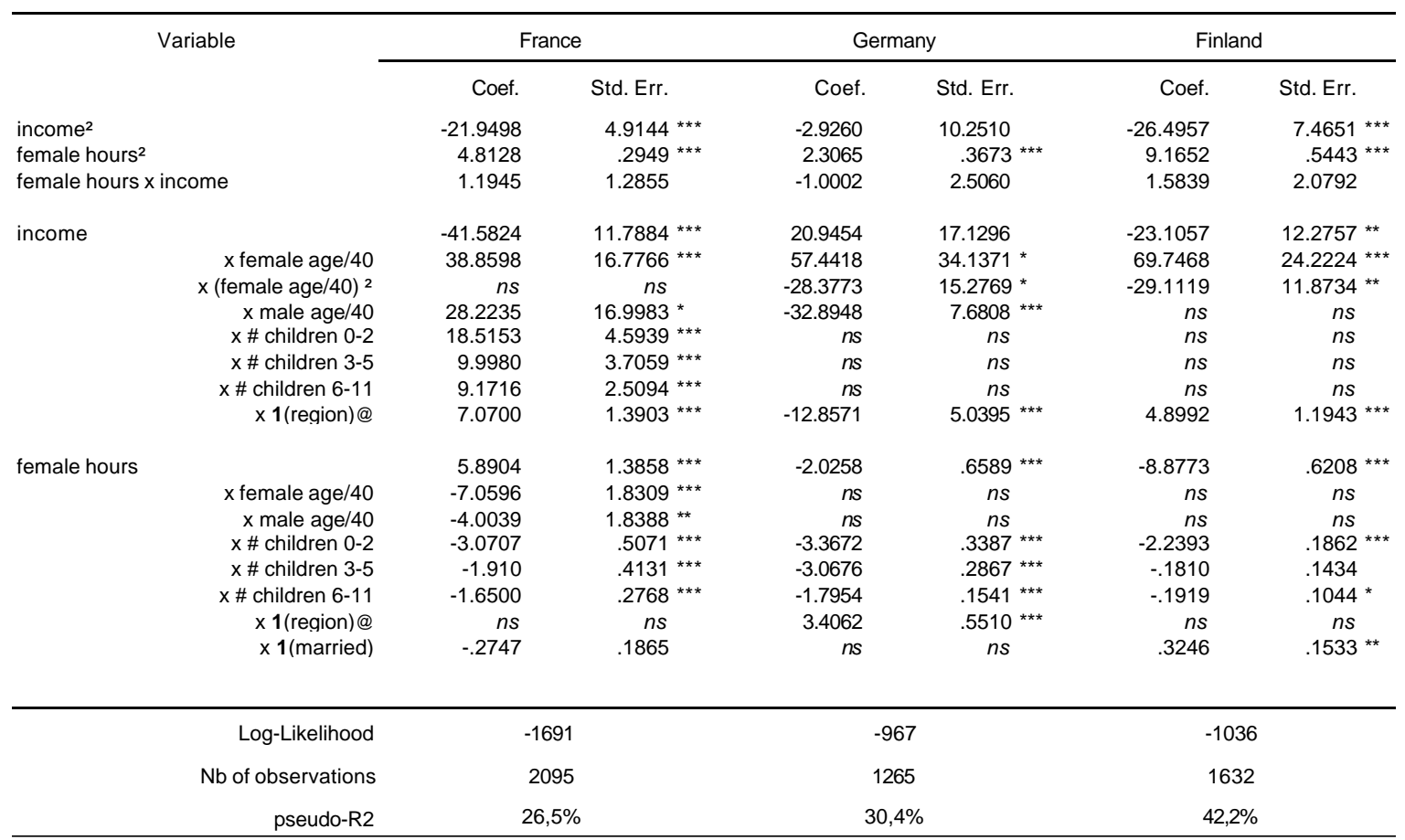

Level of significance: ${ }^{*}=10 \%,{ }^{* *}=5 \%,{ }^{* * *}=1 \%$

@ : the dummy 'region' corresponds to Paris area for France, Helsinki area for Finland and East Germany for Germany.

$n s$ : covariates were excluded from the estimation as they were highly non-significant, hence increasing the variance of the predictions from the estimated model 
Table 13: Estimation Results for Single Women

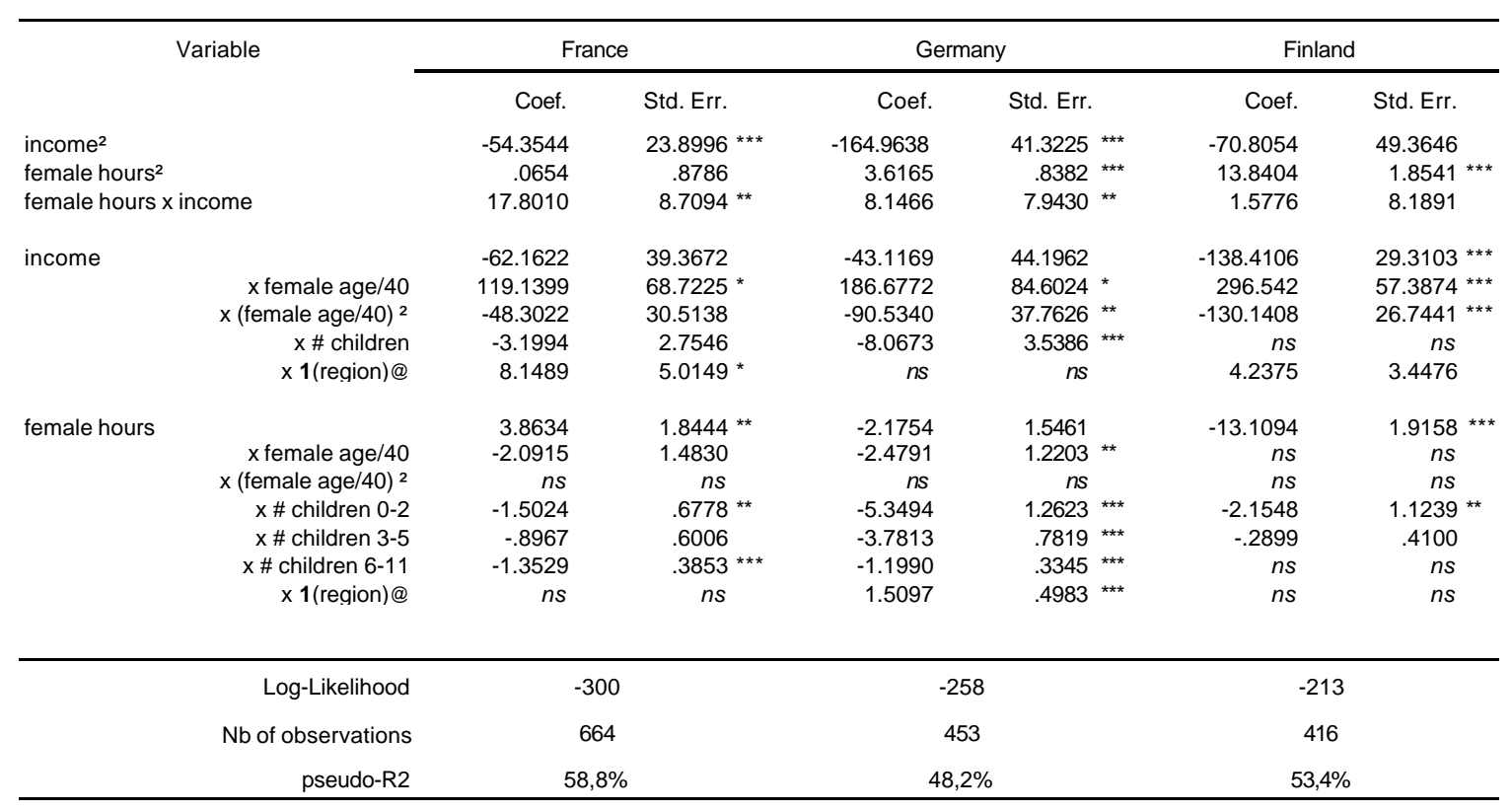

Level of significance: ${ }^{*}=10 \%,{ }^{* *}=5 \%,{ }^{* * *}=1 \%$

@ : the dummy 'region' corresponds to Paris area for France, Helsinki area for Finland and East Germany for Germany.

$n s$ : covariates are excluded from the estimation if they are highly non-significant, hence increasing the variance of the predictions from the estimated mode 
costs of work. ${ }^{55}$ Dynamic aspects or demand-side rationing can also be captured in the estimates and interfer with the purely static and labor supply interpretations.

Goodness-of-fit is expressed in terms of the pseudo-R2 as often in nonlinear types of models. ${ }^{56}$ This is a measure in $[0,1]$ of the distance between the maximized value of the log-likelihood and the log-likelihood when all parameters are set to zero. This indicator is helpful for the specification search as it summarizes the fit of a given specification in a single value. However, the absolute value is itself not very informative (see Green, 2000) and it cannot be used to rank the quality of estimations across countries. ${ }^{57}$

\section{Some Limitations of the Approach}

It is worth noting that the assumption that male labor supply is fixed can bias the estimations for women in couple. Indeed, beyond the usual critics to the second-earner approach, it can also be argued that female labor supply may be linked to some extent to the labor supply of husbands by some matching of unobservable characteristics between spouses. For instance, women with inactive husbands tend to work less than women with working partners, ceteris paribus (i.e for the same level of cumulated male and non-labor incomes). This heterogeneity cannot be identified with the few household characteristics available. In particular, it is difficult to know if the matching between spouses is related to preferences, to the productivity or both. This bias is partially reduced here by the fact that the husband's wage rate is introduced in the estimation used to predict wage rates for female non-workers. A better correction of this bias would require to predict wage rates for all women and not only for inactive ones.

Other important limitations of this setting are worth mentioning even though common to most related studies in the literature. Firstly, some labor market constraints are not addressed in the present study and in particular rationing in the choice of hours. Information on actual as well as desired hours of work is necessary to capture these aspects and to disentangle supply and demand sides. The necessary data is unfortunately not provided by the datasets at hand. ${ }^{58}$ Secondly, we implicitly assumed that before-tax hourly wage rates do not vary with work hours. ${ }^{59}$ Thirdly, prices/wages are assumed not to change with the reforms. Our results can be seen as valid in the middle-term, the short-term implying no

\footnotetext{
${ }^{55}$ The usual practice consists in adding state-specific dummies (or only part-time dummies, as in Van Soest, 1995) which could represent the variable costs of work (e.g. childcare costs) or the specific disutilities from job search (e.g. when parttime jobs are relatively scarse, in the Dutch case studied by Van Soest, 1995). We tried such specification but it turned out that the new coefficients did not prove significantly different from zero and dramatically increased the standard-error of our predictions.

${ }^{56}$ Accurate predictions are usually a matter of trade-off. To increase the number of variables in $Z_{i}$ for a better fit would indeed lead to fairly less precise predictions of labor supply elasticities or responses to the reforms. The compromise we made - mostly influenced by the necessity to obtain precise predictions - was to take out of the specification all interacting socio-demographic characteristics whose coefficient were highly unsignificantly different from zero.

${ }^{57}$ Other measures are used in a multinomial setting and in particular the comparison for all discrete choices their observed frequency by the average estimated value over all households. The probabilities predicted for all countries correctly represent the proportions of the samples. The generalized R2 for each choice (the percentage of observed variance explained by the model) seem reasonable except for the prediction of part-time work. This is similar to recent findings in the literature (Laroque and Salanié, 2002, for France; Bonin, Kempe and Schneider, 2003, for Germany). These tables are available upon request.

${ }^{58}$ Even when desired hours are available, it is difficult to make sure that individuals' answers to the preferred hours question only reflect preferences (and are not themselves affected by some constraints). Desired hours are used for instance in Ilmakunnas and Pudney (1990).

${ }^{59}$ This hypothesis is relaxed in Moffit (1984), Tummers and Woittiez (1991) and Ilmakunnas and Pudney (1990). The authors find that before-tax wage rates are lower for part-time jobs. In the countries we examine, most wages are determined by collective bargaining within branches or sectors so that discrimination between full-time and part-time workers is less likely to occur.
} 
behavioral responses (first-round analysis) and the long-run incorporating general equilibrium effects. ${ }^{60}$ In addition, it is assumed that employers will not offset the net gain of the benefit by lowering hourly wages. ${ }^{61}$ Fourthly, the model is static and does not account for life cycle aspects which could justify that some households take a job even when financial gains are null.

Other aspects are worth mentioning. We focus here on financial incentives only and ignore the type of institutional arrangements chosen as a framework to implement the reform, even though those may be determinant to the effectiveness of the policies. The administrative arrangement for the payment of the transfers may be important and in particular the frequency of payment. ${ }^{62}$ The form chosen for the MWP policies also has a non negligible role. Three forms of employment-conditional transfers are usually used by governments: wage subsidies, in-work benefits or refundable/non-wastable tax credits. In our simulations, the form given to each policy - purely illustrative - has been simply pragmatic. An individual policy in the form of a tax credit - as in the recent Belgian reform - would require individualized income tax schemes which is not the case in France or Germany. To keep the implementation in all three countries as simple as possible, a wage subsidy seemed a natural candidate. As for the family-based reform, we have used the popular British reform as a benchmark, and have hence chosen a refundable tax credit instead of an in-work benefit. ${ }^{63}$ This is also motivated by the fact that in-work benefits conditional on claims have posed serious take-up problems. In the recent years, policy makers have rather opted for tax credit administered by fiscal authorities and paid directly through the wage packet in Paid As Your Earn systems. Notice that as in Blundell et al. (2000), we have assumed full take-up of both transfers.

\footnotetext{
${ }^{60}$ Using a CGE model for Germany, Boeters et al. (2003) find that general equilibrium effects are rather modest when simulating MWP policies (a cut in social assistance and a reduction in marginal tax rates). Partial equilibrium approximations are justified insofar as only a small number of individuals are affected, which is usually the case with this type of reforms.

${ }^{61}$ To limit this adverse effect, minimum wage legislation has recently been implemented in the UK.

${ }^{62}$ See comments from Duncan (2000) an Dilnot and McCrae (1999).

${ }^{63}$ Note that this choice may well have implications as far as intrahousehold aspects are concerned. Indeed, in the beginning the Family Credit was payable to the main carer of the children (most often the wife), but the WFTC was paid as a refundable tax credit included in the pay package of the main earner (most often the husband). If we accept that who controls resources matters for intrafamily distribution, the latter reform should be seen as a 'purse to wallet' transfer to families. This issue is addressed in Blundell, Myck and Lechene (2002) using the methodology developed in Laisney (2002, ed.) to simulate a collective model of labor supply. It is interesting to note that the 2003 reform in the UK precisely split the credit in two, a child tax credit going to the main carer and a working tax credit to the main earner.
} 